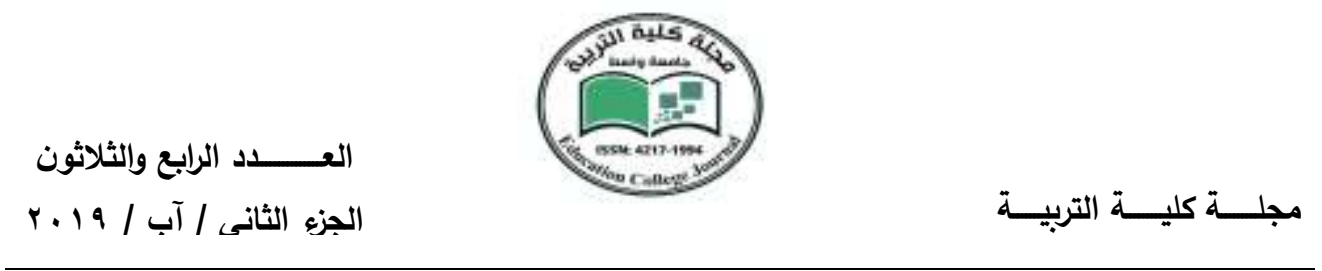

\title{
البعد الاجتماعي للتنمية المستدامة ومؤشرات قياسه (دراسة تحليله لأحياء سكنية مختارة في مدينة الكوت)
}

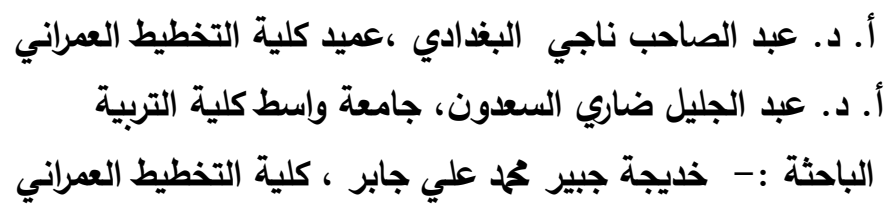

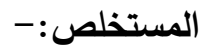

تعد الابعاد الاجتماعية ضرورية لعملية التتمية الاجتماعية، اذ أصبح مفهوم التتمية يرتكز على الابعاد الاجتماعيـة بعدما كان يقتصر سـابقا على الابعاد الاقتصـادية فقد أخذت التتميـة تركز على ملى

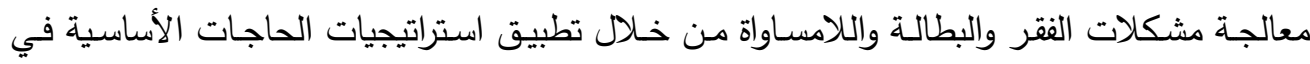
اعداد خطط التتمية وتتفيذها ومتابعتها. فقد اثبتت الدراسات ان الابعاد الاجتماعية لها دور كبير في نجاح او أخفاق عملية التتمية، وذلك ان عدم مرونة البناء الاجتماعي والنظم الاجتماعية وشيوع أنماط من العادات والتقاليد وخاصـة تلك التي تكسب الافراد الاستسلام وعدم بذل أي جهد من اجل التغير تقتضي على خطط التتمية في مهدها، وان مؤشرات قياس التتمية تعتمد على مؤشرات اجتماعية أخرى عديدة ومصاحبة لها نفس الدرجة من الأهمية كالمستويات التعليمية والصحية .... الخ.

\section{Abstract- :}

Social aspects are essential to the process of social development. The concept of development is based on social dimensions. It was previously confined to economic aspects. Development has focused on addressing the problems of poverty, unemployment and inequality through the application of basic needs strategies in the preparation, implementation and follow-up of development plans.

Previous Studies have shown that the social aspects have a big role in the success or failure of the development process. The inflexibility of social construction and social systems and the prevalence of patterns of customs and traditions, especially those that earn individuals surrender and the lack of any effort for change require the development plans in the beginning. Indicators of measuring development depend on many other social indicators and accompanying the same degree of importance, such as educational and health levels. 
العـــــــد الرابع والثلاثون

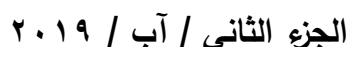

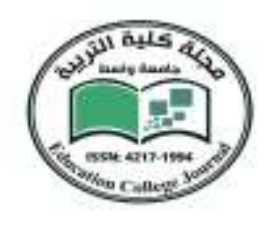

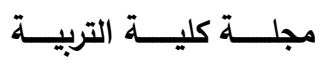

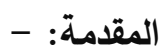

تعـد التنميــة قضــية حضــارية وعمليــة شـاملة متعـددة الابعـاد الاقتصــادية والاجتماعيـة

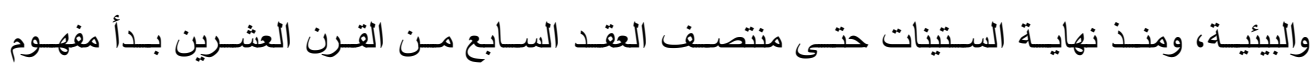
التتميـة يرتكز على الابعـاد الاجتماعيـة بعـدما كـان يقتصـر في المرحلـة السـابقة على الابعـاد

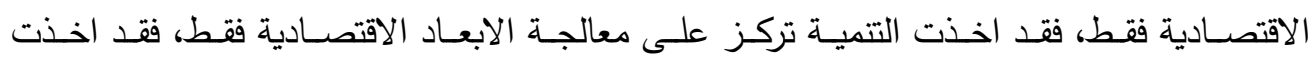

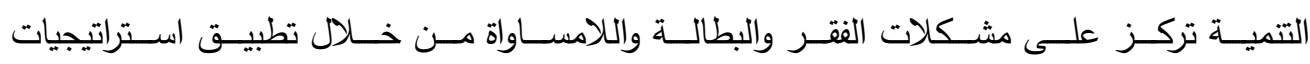
الحاجات الاساسية والمشاركة الثعبية في اعداد خطط التتمية وتتفيذها ومتابعتها.

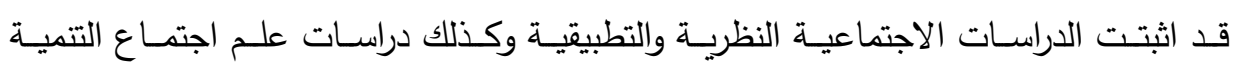
ان الابعـاد الانسـانية والبشـرية والاجتماعيـة لهـا دور كبيـر فـي نجـاح او اخفـاق عمليـة التتميـة.

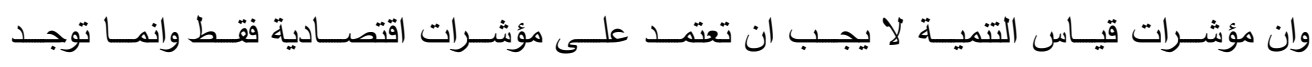

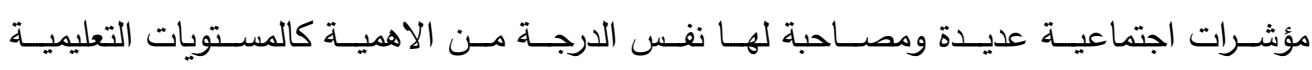
والصحية . مون.

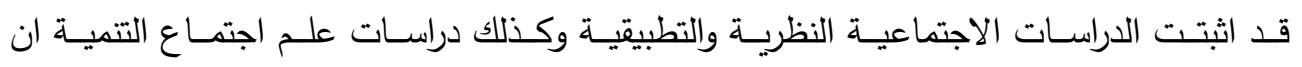
الجوانـب الانسـانية والبثـرية والاجتماعيـة لهـا دور كبيـر فـي نجـاح او اخفـاق عمليـة التتميـة.

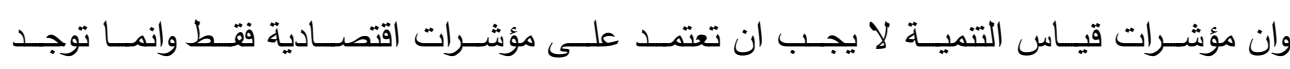

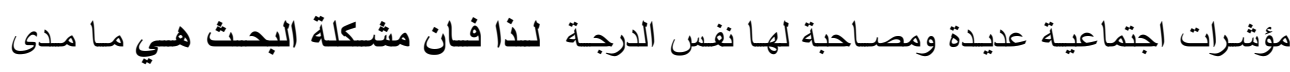

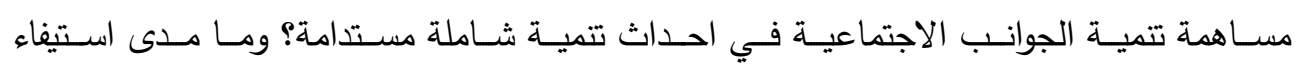

مدينة الكوت لمتطلبات الابعاد الاجتماعية للتمية ؟

امـــا فرضـية البحــث هـي ان تتميـة الجوانـب الاجتماعيـة تسـاهم فـي احـداث تتميـة

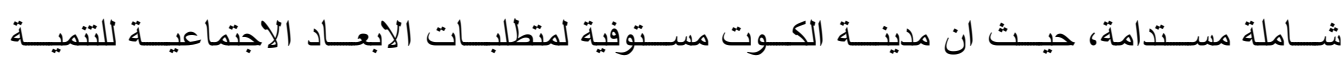

المستدامة.

وعليـهـ فـان هـدف البحــث هــو ابـراز أهميـة تتميـة الجوانـب الاجتماعيـة فـي تحقيـق التتمية المستدامة وتكوين صورة عن واقع مدينة الكوت في ظل هذه الابعاد. 
العـــــــد الرابع والثلاثون

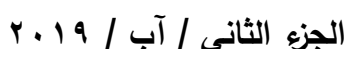

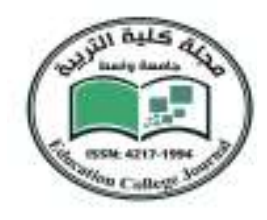

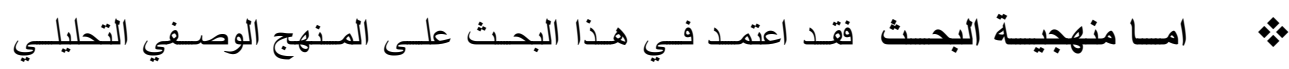
للوقـوف على مختلـف المفــاهيم ومحاولــة تحليلهـا بالإضــافة الـى الاسـتعانة بـبعض البيانـات الاحصائية عن مختلف المؤشرات الاجتماعية للتمية المستدامة في الكوت. • امــا الــدود المكانيــة والزمانيــة للبحـث فتتمثـل فـي الحـدود البلديـة لمدينـة الكـوت والتي يمثلهـا المخطـط الاسـاس Master Plan لمدينـة الكـوت والـذي يثـغل مسـاحة قدرها 70كيــو متـر مربـع والتـي يحـدها مـن الثـرق هـور الثـويجة ومـن الغـرب نهـر الغـراف ومـن

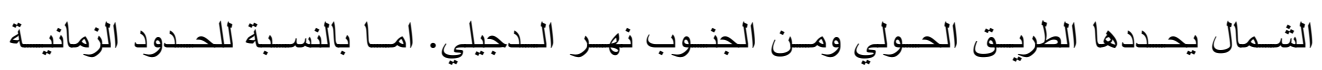

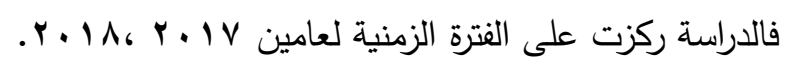

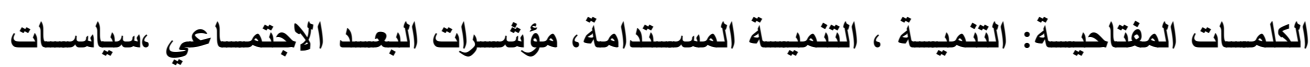
التنمية وشركائه.

\section{الفصل الاول :- المفاهيم النظربة للتنمية المبحث الاول :- مفهوم التنمية ، انواعها}

1-1 مفهـوم التنميـة : هنـاك مفـاهيم عديدة للتنميـة، جـاء بها عدد مـن الباحثين في مختلف الاختصاصـات العلمية، تهدف الى بيان مفهوم التتمية ودورها في بناء المجتمع واحداث التغيرات. لقد جرت عدة محاولات لتحديد معنى التتمية فهنالك من يقول بان التتمية هي عبارة عن عملية تستند إلى الاستغلال الجيد للموارد بقصد إقامة مجتمع حديث

بينما يلاحظ البعض ان التتمية هي عملية للنهوض بالحياة الاقتصادية والاجتماعية ، ويرى آخرون

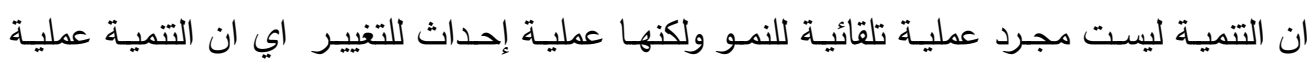
مخططة وليست تلقائية. ا-r انواع التمية : ان أنواع التتمية لم تظهر جميعها خلال مدة واحدة بل هنالك نوع او اخر قد سبق ظهور الأنواع الأخرى، ثم ازدادت الدراسـات عن التتمية وتوسعت كثيرا. فقد ظهرت التتميـة الاقتصـادية. أولا، ثم التتميـة الاجتماعيـة ثانيـا، وبعـد إدراك البـاحثين التأثيرات المتبادلــة للجـانبين الاقتصادي والاجتماعي أحدها في الأخر ظهر نوع ثالث أطلق عليه بالتتمية البشرية. وبعد التطور 
العـــــــد الرابع والثلاثون

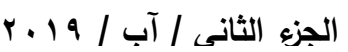

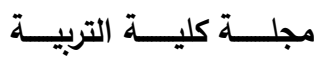

الحاصل وتأكيد العلماء أن ثمار التتمية يجب ان تأخذ بنظر الاعتبار التركيز على ان تنال الأجيال

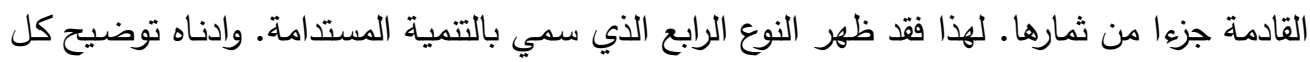
من هذه الأنواع على حده.

اولا: التتمية الاقتصادية : تعد التتمية الاقتصادية النوع الاكثر اهمية من مواضيع التمية المختلفة ،

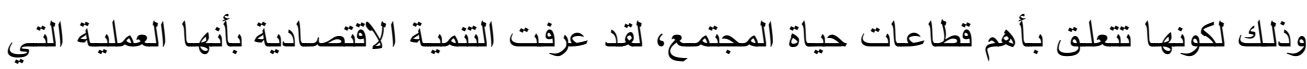
يرتفع بموجبها الدخل القومي الحقيقي خلال مدة من الزمن.

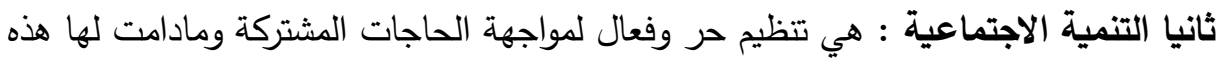

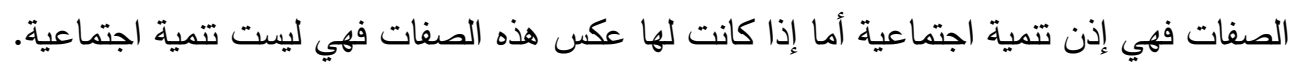

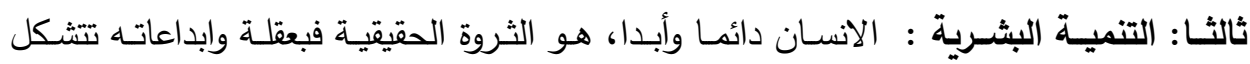

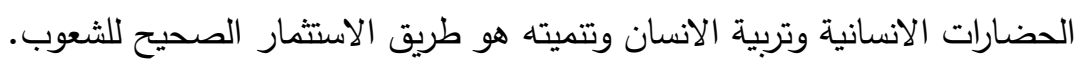

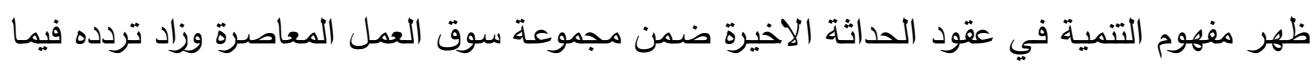

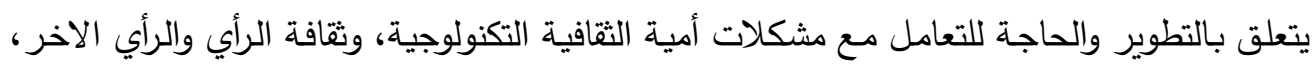
وثقافة التواصل الفعال. ثم انتشر أول تقرير عن التتمية البشرية في ادبيات الامم المتحدة عام . 199 حيث ذكر فيه نصا:( (الثعب هو الثروة الحقيقية لأي أمة)).

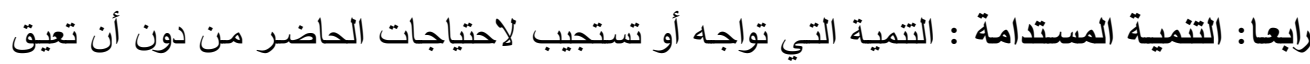

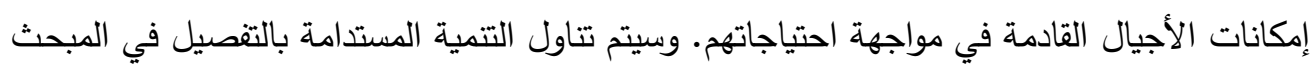
اللاحق. 
العــــــد الرابع والثلاثون

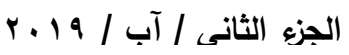

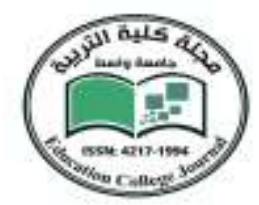

\section{المبحث الثاني}

\section{التنمية المستدامة، مفهومها، خصائصها، مميزاتها، اهدافها}

ץ- ا مفهوم التنمية المستدامة: نشأت فكرة التتمية المستدامة عندما بدا العالم يفطن الى أن عملية التتمية أخذت اتجاها اقتصاديا بحتا دون النظر الى التأثيرات الناجمة الضارة بالبيئة، عرف اتحاد الحفاظ العالمي (البرنامج البيئي للأمم المتحدة) سنة الو9 19 التتمية المستدامة بأنها: تقوم بصيانة وتحسين جودة الحياة البشرية من الناحية الاجتماعية والاقتصادية والبيئية ومساعدة الموارد الموجودة.

حيث ترى الباحثة ان التتمية المستدامة تمثل: - (تلبية الاحتياجات للأجيال الحالية حسب الامكان دون التأثير على قدرة الاجيال القادمة لتلبية احتياجاتهم او خفض مستوى معيشتهم وان يتمتعوا ببيئة صحية مناسبة او نظيفة، وحياة حرة كريمة تحقق السعادة للإنسان). فالتنمية المستدامة هي الاستعمال المثالي الفاعل لجميع المصـادر الثلاثة (البيئة والاقتصـاد والحياة الاجتماعية) للمستقبل البعيد، مـع التركيز على حياة أفضل ذات قيمة عالية لأفراد المجتمع كافة في الحاضر والمستقبل. r-r - r - r - خصائص التمية المستدامة: طرح مصطلح التتمية المستدامة عام ع ع 19 في أعقاب مؤتمر ستوكهولم، الذي عقبته قمة ريو للمرة الأولى حول البيئة والتتمية المستدامة الذي أعلن عام r99 19 عن خصائص التتمية المستدامة التي تتلخص فيما يلي: أ - هي تتمية يعتبر البعد الزمني هو الأساس فيها، فهي تتمية طويلة المدى بالضرورة. ب- هي تتمية ترعى تلبية الاحتياجات القادمة في الموارد الطبيعية للمجال الحيوي لكوكب الأرض. ج - هي تتمية تضع تلبية احتياجات الأفراد في المقام الأول. د - وهي تتمية تراعي الحفاظ على المحيط الحيوي في البيئة الطبيعية.. هـ - هـي تتميـة متكاملـة تقوم على التسـيق بين سلبيات استخدام الموارد، واتجاهـات الاستثمارات والاختيار التكنولوجي. و - وجود علاقة تكاملية بين البيئة من ناحية والتنمية من ناحية اخرى. س -للتمية المستدامة طرق عقلانية لاستغلال الموارد سواء كانت متجددة او غير متجددة لضمان تحقيق التوازن بين مختلف الجوانب. ش - للتتمية المستدامة أهداف تسعى لتحقيقها من خلال اليات فعالة ومبادي تقوم عليها. 
العـــــــد الرابع والثلاثون

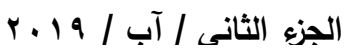

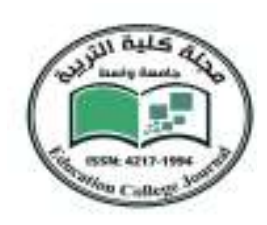

ص - للتمية المستدامة أبعاد بيئية واجتماعية واقتصـادية متثابكة ومتداخلة مع بعضها البعض في أطار تفاعيلي يتسم بالضبط والتتظيم والترشيد. ض -يعتبر مصطلح التتمية المستدامة مصطلح عالمي. ر - التنمية المستدامة هي تتمية شاملة ومسؤولية مشتركة..

ز - التمية المستدامة تعني احداث تغيرات في كمية متوسط نصيب الفرد في الدخل الحقيقي. r - r الهمية التنمية المستدامة : تعتمد عملية التتمية المستدامة في أي مجتمع من المجتمعات على مصدرين أساسين هما الطبيعة والإنسان ( موارد طبيعية وموارد سكانية ) وهذان هما جناحا التتمية اللذين بهما إما تخلق في أفاق الرخط والرفاهية، وإما تهبط في مجال العجز والتخلف، وتختلف المجتمعات في حيازة هذين المصدرين كما وكيفا: وتأتي أهمية التتمية المستدامة بالنسبة لاستغلال الموارد الطبيعية من ارتباطها بعاملين أساسيين

$$
\begin{aligned}
& \text { - : } \\
& \text { التز ايد المطرد في عدد السكان. } \\
& \text { • زيادة الحاجات تبعا للتطور الفكري والحضاري. }
\end{aligned}
$$

ץ-عميزات التتمية المستدامة : ان التتمية المستدامة هي التتمية الحقيقية ذات القدرة على الاستمرار

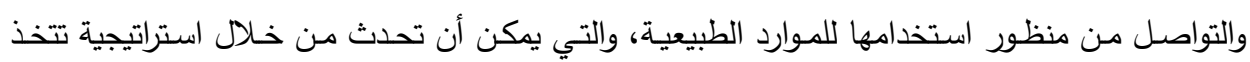

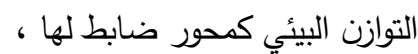

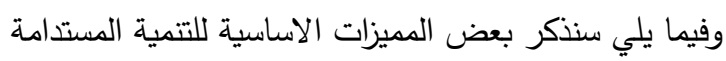

• أثد تدخلا وأكثر تعقيد عن التتمية وخاصة فيما يتعلق بما هو طبيعي وما هو اجتماعي.

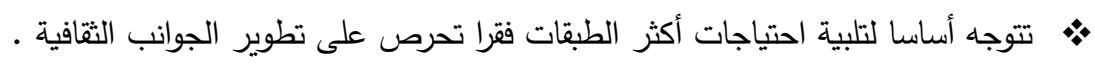

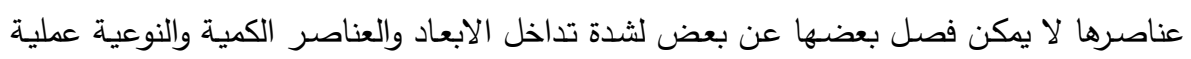

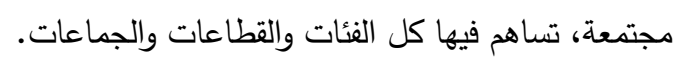

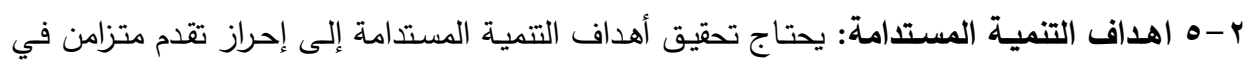

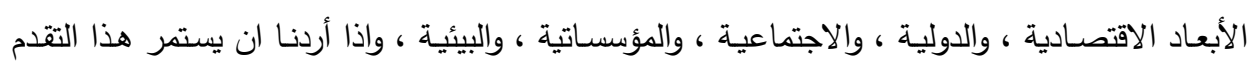

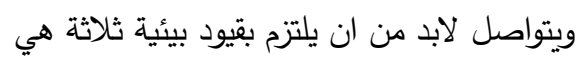

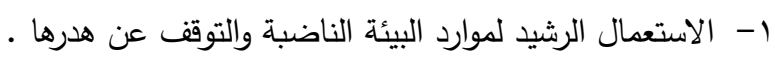

r- الالتزام في استهلاك الموارد المتجددة بحدود قدرة هذه الموارد على تجديد نفسها.

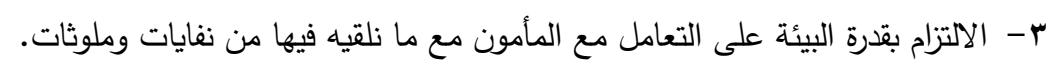


العـــــــد الرابع والثلاثون

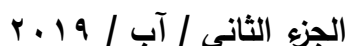

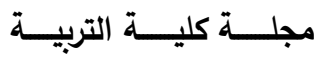

\section{المبحث الثالث}

مؤشرات الابعاد الاجتماعية للتمية المستدامة وقياسها

ان المؤشرات الاجتماعية للتنمية لها اهمية كبيرة في دراسات التنمية المستدامة ، والهمها: 1-T المؤشرات الاجتماعية : وتتضمن عدة مؤشرات

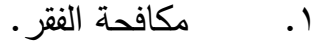

$$
\begin{aligned}
& \text { أ- معدل البطالة. } \\
& \text { ب- مؤشر الفقر البشري. }
\end{aligned}
$$

ت- عدد السكان الذين يعيشون تحت خط الفقر .

r. الدينامية الديموغرافية والاستدامة ويعبر عنها بمعدل النمو السكاني.

r. تعزيز التعليم والوعي السنوي والتدريب ويتضمن ما يأتي: -

أ- معدل الإلمام بالقراءة والكتابة بين البالغين.

ب- - النسبة الإجمالية للالتحاق بالمدارس الثانوية.

ء. حماية صحة الإنسان وتعزيزها ويقسم إلى: -

أ- متوسط العمر المتوقع عند الولادة.

ب- عدد السكان الذين لا يحصلون على المياه المأمونة.

ت- عدد السكان الذين لا يحصلون على الخدمات الصحية.

ث- عدد السكان الذين لا يحصلون على المرافق الصحية.

ع- تعزيز التنمية المستدامة للمستوطنات البشرية ويتمثل بنسبة السكان في المناطق الحضرية. 
العــــــد الرابع والثلاثون

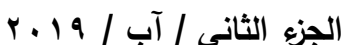

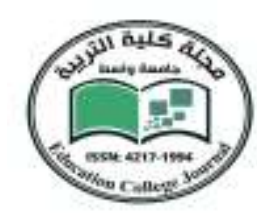

\section{المبحث الرابع \\ سياسات التنمية الاجتماعية وشركائها}

؛ - اسياسات التنمية الاجتماعية: نظام يتضمن عدد من الانثطة الموجهة للإشباع حاجات سكان المجتمع •

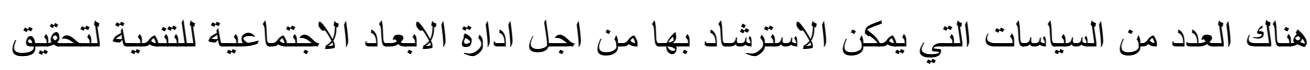
تتمية شاملة مستدامة وهي:

ا- السياسـات الاجتماعيـة للإقـلال مـن الفقر : لقد اثبتت الدراسـات ان تغير الفقر مـع الزمن

يثمل مكونين هما: مكون النمو الاقتصادي ومكون التوزيع.

ץ- السياسة التعليمية: السياسة التعليمية واحدة من اهم جوانب السياسة الاجتماعية التي تلجأ لها البلدان المتخلفة كي تعيد ترتيب نظم التعليم فيها بالتغيير واعادة الصياغة والاصلاح، بأمل تجاوز واقع التخلف .

ب- السياسـة الصـحية: الاستثمار في أنثأ مراكز رعايـة الامومـة والطفولة، التوعيـة بالعـادات الصحية السليمة والنظافة والوقاية من الامراض.

ع - السياسة السكنية: توفير المساكن الصحية المناسبة لأهالي المجتمع، توفير مراكز الخدمات العامـة كالمياه والصرف الصحي والكهربـاء، تشجيع الثباب على المشاركة في مشروعات

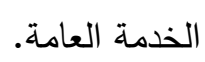

ه - سياسـات ديموغرافيـة: تسطير برامج التوعية للسكان تهدف الى تتظيم النسل والاستغلال الامثل للطاقات البثرية المتوفرة.

ع - - شركاء التنمية الاجتماعية : من المفاهيم الحديثة المطروحة في مجال التتمية مفهوم (شركاء التتمية ) حيث يوجد شركاء في مجال التتمية وهم كل الافراد والمجموعات والمنظمات

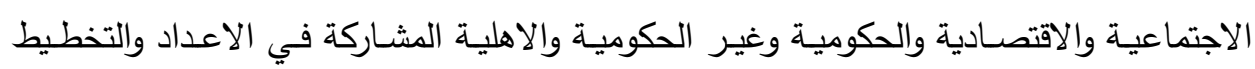
والتتفيذ والدعم ، المعنين والمستفيدين من عملية التتمية. اولا: الحكومـة المركزيـة: تخصيص الميزانيات المناسبة للارتقاء بالمناطق المتدهورة، توفير التقنيات 
العـــــــد الرابع والثلاثون

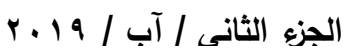

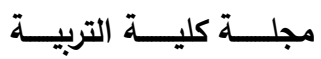

ثانيا: الحكومة المحلية: الادارة والاشراف على مشروع الارتقاء، توفير قاعدة المعلومات عن الاوضاع المحلية، تحديد الاحتياجات المحلية الملحة ثالثا: المجتمعـات المحلية: تحديد المشاكل والاحتياجات، المساهمة المالية في تكاليف المشروع، تيسير تتفيذ المشروع، المساهمة في تتفيذ المشروع، ابتكار الحلول الواقعية. رابعـا: المنظمـات غيـر الحكوميـة: توفي التمويـل ورؤوس الامـوال تـوفير المتخصصـين والخبـراء المتبرعون، تحديد الاحتياجات الحقيقية للسكان، تعبئة الطاقات والموارد اللازمة للتمية. خامسا: الجمعيات الاهلية: تحديد الاحتياجات المحلية الاقتصادية والاجتماعية والعمرانية. سادسـا: القيـادات الثـعبية: حثث السكان على المشاركة، توعيـة السكان، بنـاء جسور الثقـة بين ولين الاهالي والجهات المسئولة عن مشروع الارتقاء. سابعا: القطاع الخاص: تخفيف الاعباء المالية على الدولة، المساهمة في تنفيذ المشروعات السكنية ومشروعات الخدمات والمرافق العامة، مساعدة افراد المجتمع، توفير فرص عمل لحل مشاكل البطالة،

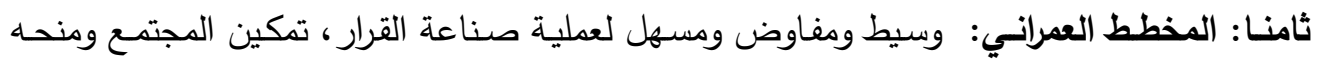
السلطة في صناعة القرار - 
العــــــد الرابع والثلاثون

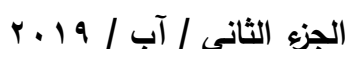

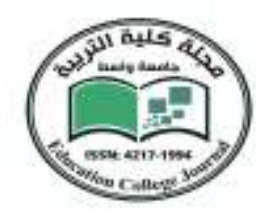

مجلــــة كليــــة التربيـــة

الفصل الثاني :- الاراسة الميدانية

بعض مؤشرات الابعاد الاجتماعية للتنمية المستدامة في مدينة الكوت (احياء مختارة)

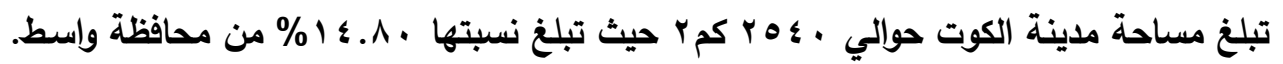

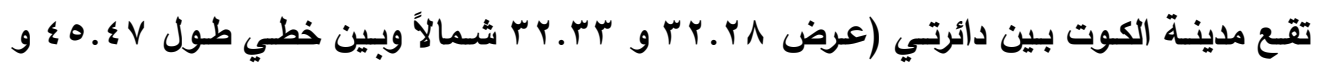

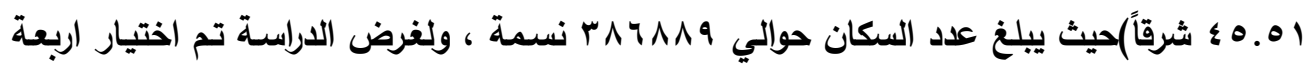

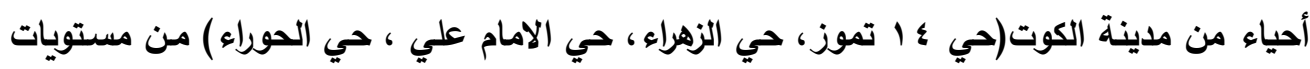

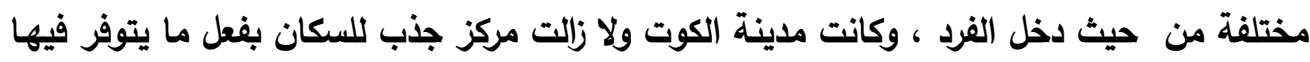

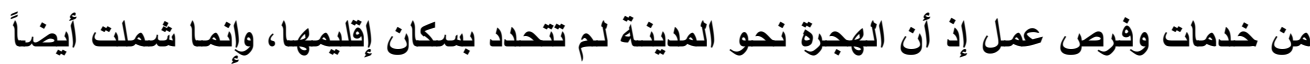

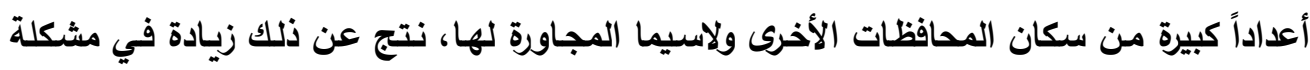
السكن في المدينة وزيادة الطلب على الأراضي السكنية والمساكن.

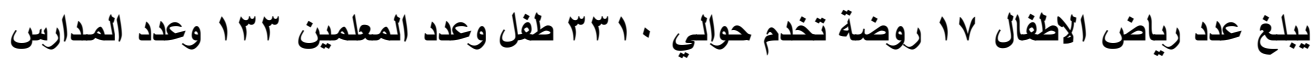

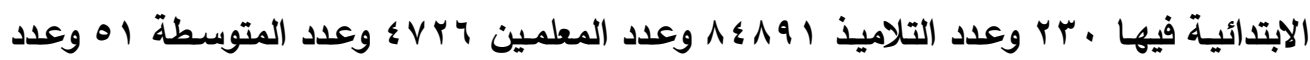

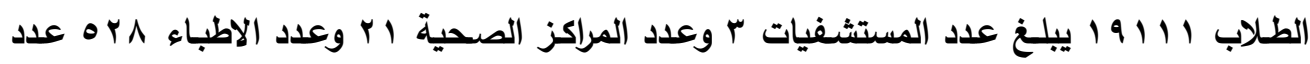

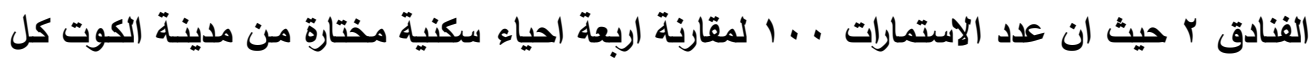

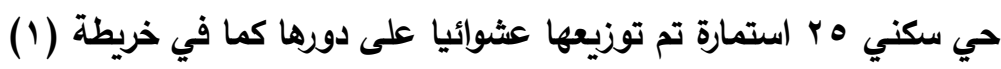
خريطة رقم (1)

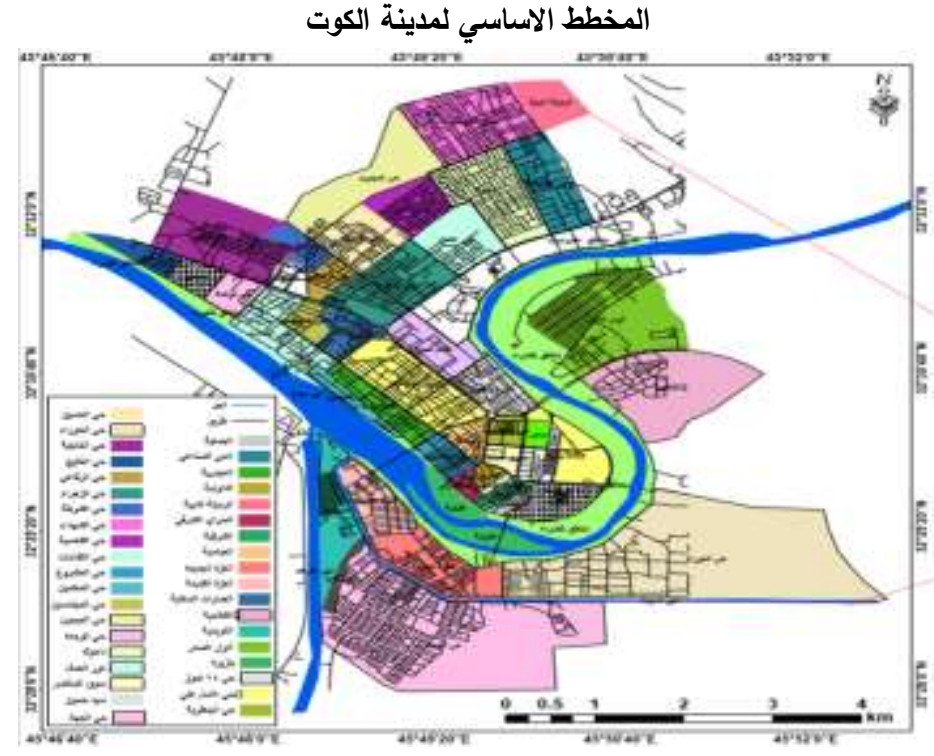

$\varepsilon r \wedge$ 
العـــــــد الرابع والثلاثون

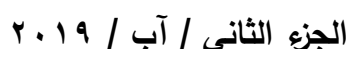

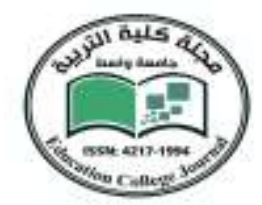

الجزع الثانمي / آب /

جدول (1) : مؤشر البطالة

المبحث الاول:- المؤشرات الاقتصادية

\begin{tabular}{|c|c|c|c|c|}
\hline \multicolumn{2}{|c|}{ نسبة الاسر التي فيها العاطلين وغير عاطلين } & \multicolumn{2}{|c|}{ الالعلرة التي فيها عاطلين وغير عاطلين عن } & \multirow[t]{2}{*}{ الاحياء السكنية } \\
\hline لا يوجد عاطلين & يوجد عاطلين & لا يوجد عاطلين & يوجد عاطلين & \\
\hline$\% \circ \wedge$ & $\% \leqslant r$ & $1 \pi$ & 14 & حي ؛ ا تموز \\
\hline$\%$ \% & $\% \circ \lambda$ & IT & $1 \pi$ & حي الامام علي \\
\hline$\% \leq \varepsilon$ & $\% 4$ & 11 & $1 \leqslant$ & حي الزهراء \\
\hline$\%^{\mu}$. & $\%$ v. & 9 & 14 & حي الحوراء \\
\hline
\end{tabular}

نلاحظ من الجدول اعلاه يثير الى ان · V\% من الاسر في حي الحوراء يوجد بين افرادها عاطلين عن العمل ويليه

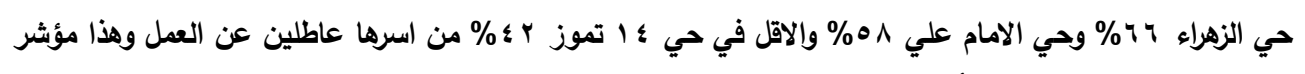
شكل (1): مؤشر البطالة في منطقة الدراسة

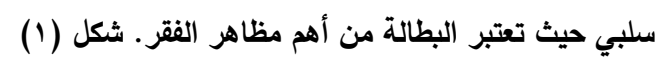

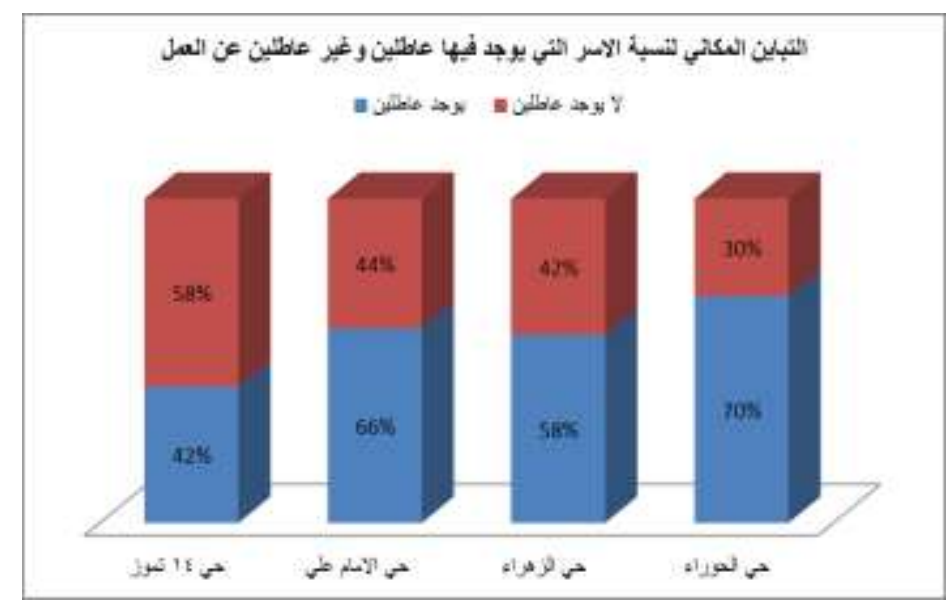


العــــــد الرابع والثلاثون

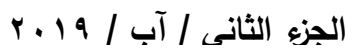

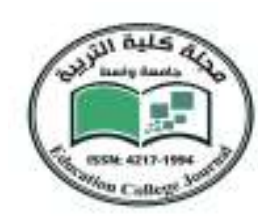

مجلــــة كليــــة التربيـــة

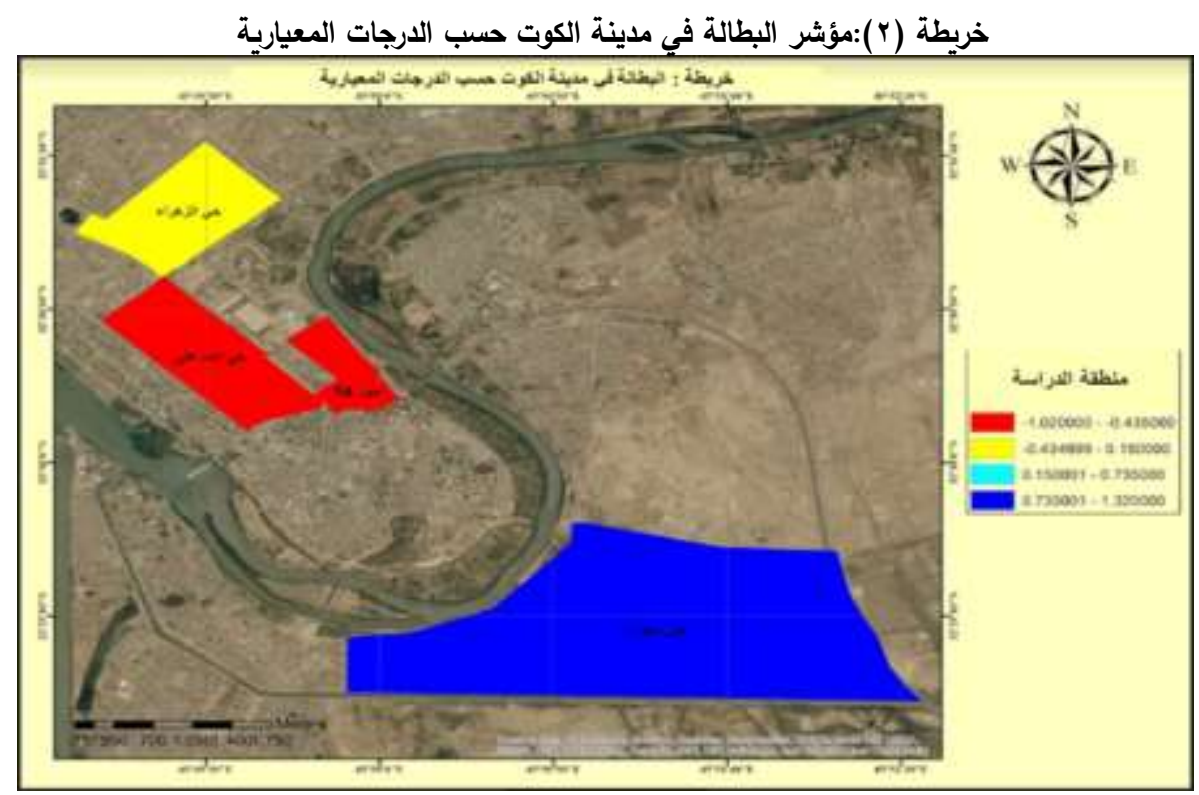

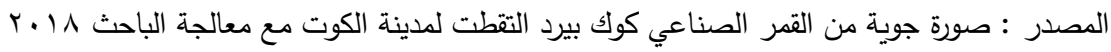

\section{ثانيا : مؤشر الاخل}

جدول (r) : مؤشر الدخل

\begin{tabular}{|c|c|c|c|c|c|c|c|c|}
\hline \multicolumn{4}{|c|}{ نسبة مستوى الاخل في العائلة } & \multicolumn{4}{|c|}{ مستوى الاخل في العائلة } & \multirow[t]{2}{*}{ القطاعات السكنية } \\
\hline اكثر من & $\begin{array}{l}-v 0 . \\
1 \ldots\end{array}$ & $v_{0} \cdot .0 \ldots$ & O...ro. & 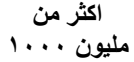 & $1 \ldots-v 0$. & vo... & O...ro. & \\
\hline$\% 09$ & $\% 19$ & $\% 17$ & $\%$ & 11 & 7 & 0 & $r$ & حي ؛ ا تموز \\
\hline$\% \bullet \wedge$ & $\%$ \% & $\% 1$. & $\% 1$. & 14 & 0 & $\varepsilon$ & $r$ & حي الامام علي \\
\hline$\% Y^{Y}$ & $\% r v$ & $\%$ \%r & $\% \leqslant$ & 7 & $\Lambda$ & $\mathrm{V}$ & $\varepsilon$ & حي الزهراء \\
\hline$\% 1$ & $\%$ & $\% 0^{\circ}$. & $\% 1$. & $\varepsilon$ & $\mathrm{V}$ & 1. & $\varepsilon$ & حي الحوراء \\
\hline
\end{tabular}

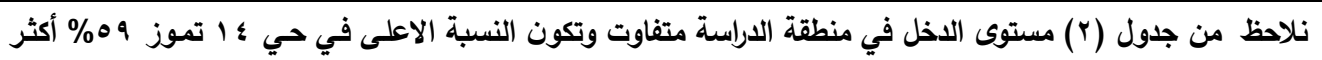

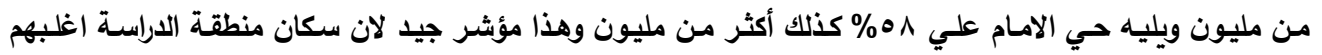

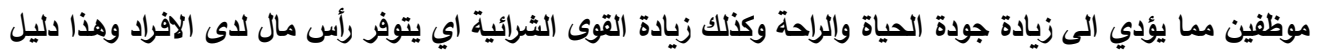

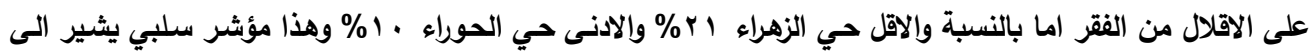

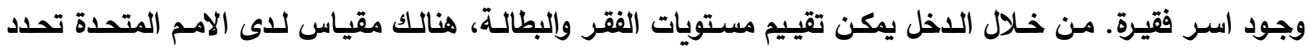

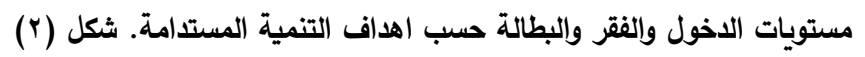


العــــــد الرابع والثلاثون

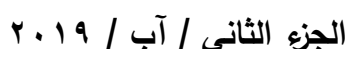

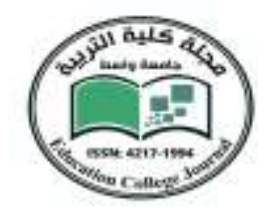

مجلــــة كليــــة التربيــــة

شكل (r): مؤشر الاخل في منطقة الدارسة

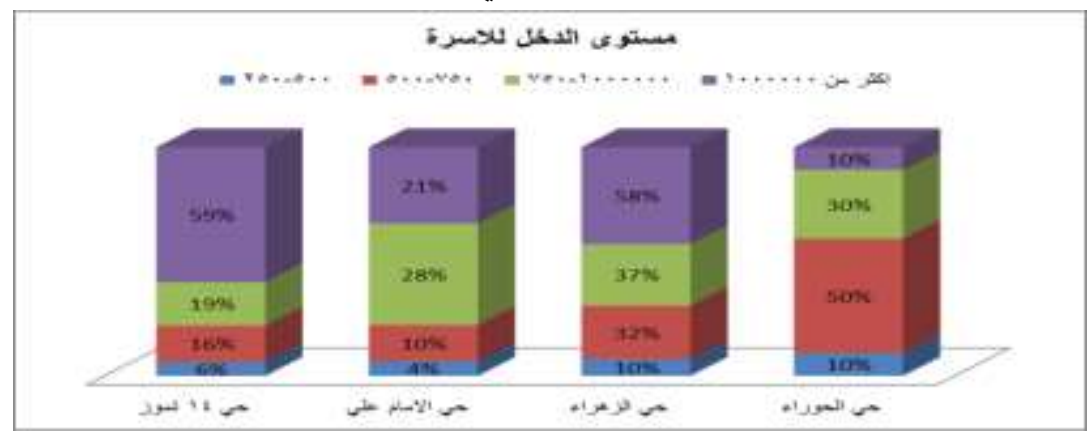

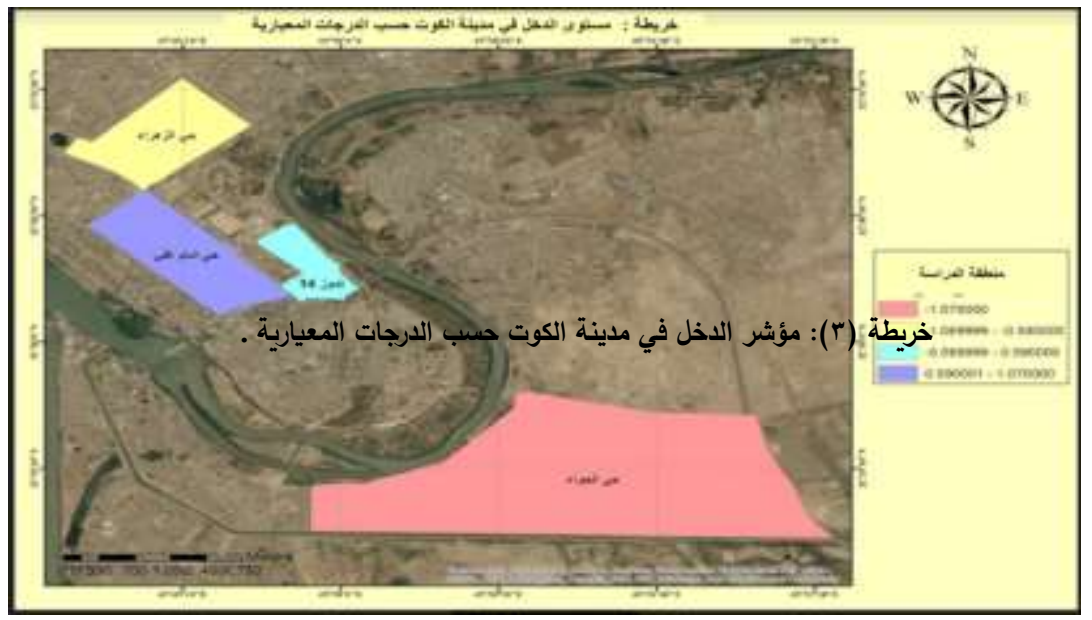

المصدر : صورة جوية من القمر الصناعي كوك بيرد التقطت لمدينة الكوت مع معالجة الباحث ^1 ـ ץ

جدول (r) : مؤشر امتلاك السيارة

ثالثا : مؤشر امتلاك الأسرة للسيارة

\begin{tabular}{|c|c|c|c|c|}
\hline \multicolumn{2}{|r|}{ النسب } & \multicolumn{2}{|c|}{ وسائط النقل } & \multirow[t]{2}{*}{ لاحياء السكنية } \\
\hline لاتمتلك & تمتلك & لاتمتلك & تمتلك & \\
\hline$\% 1$. & $\% 9$ & $\varepsilon$ & YI & حي ؛ ا تموز \\
\hline$\% 1 \wedge$ & $\%$ \%रr & 0 & $r$. & حي الامام علي \\
\hline Tr & $\% \%^{\vee \wedge}$ & $\mathrm{v}$ & 11 & حي الزهراء \\
\hline$\%$ ro & $\%$ vo & 1. & 10 & حي الحوراء \\
\hline
\end{tabular}

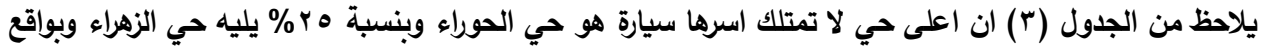

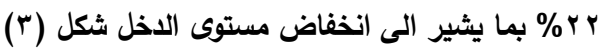




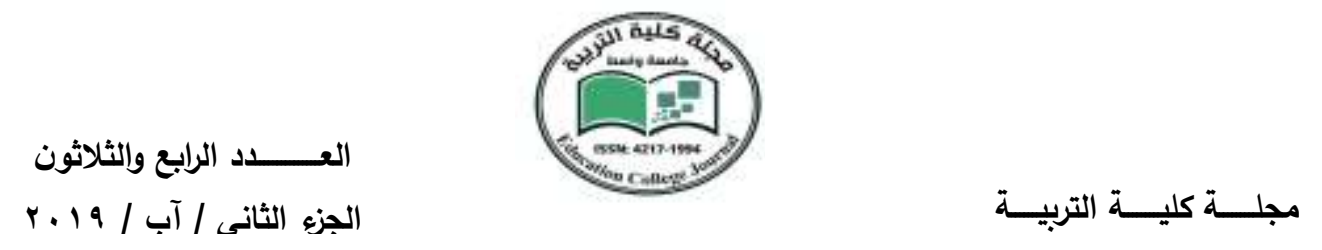

شكل (r): مؤشر امتلاك الاسرة للسيارة في منطقة الدراسة

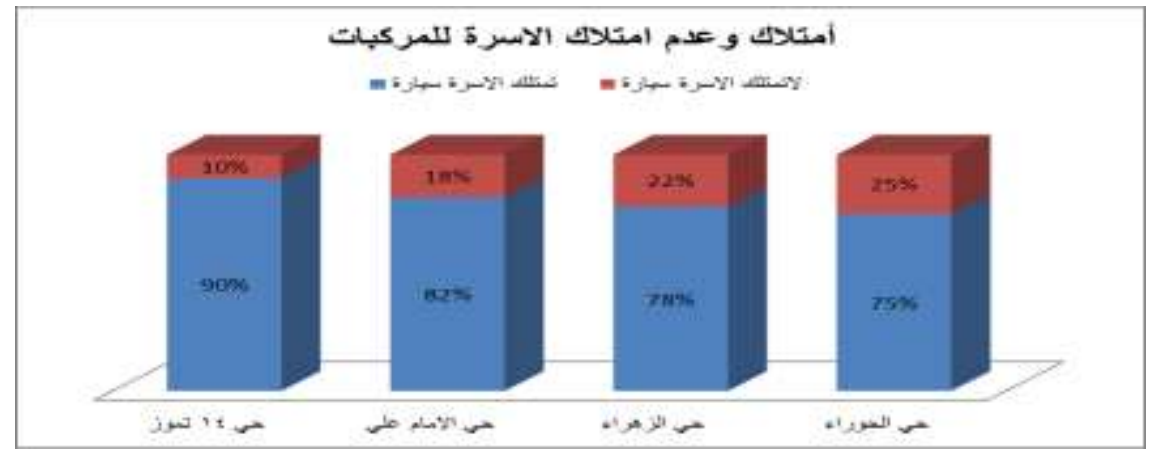

خريطة (r) : مؤشر امتلاك الميارة في مدينة الكوت حسب الدرجات المعيارية

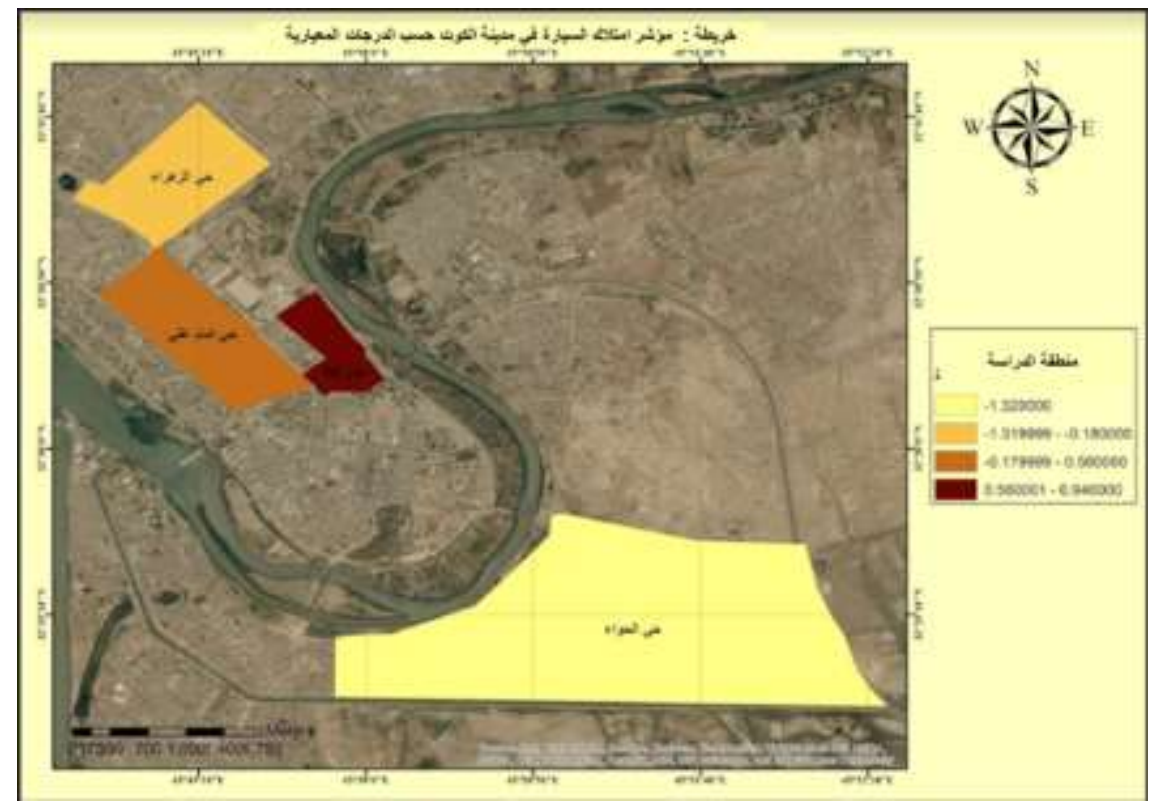

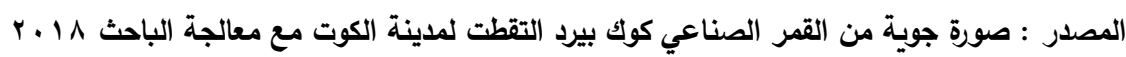


العـــــــد الرابع والثلاثون

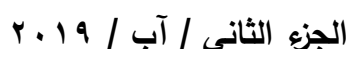

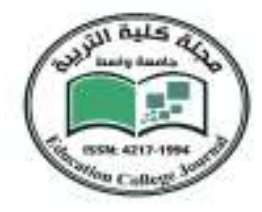

جدول (؛) : مؤشر مستوى الخدمات التعليمية في منطقة الدارسة

\begin{tabular}{|c|c|c|c|c|}
\hline \multicolumn{2}{|c|}{ نسبة الخدمات التعليمية في منطقة الدراسة } & \multicolumn{2}{|c|}{ الخدمات التعليمية في منطقة الاراسة } & \multirow[t]{2}{*}{ الاحياء السكنية } \\
\hline غير متوفرة & متوفرة & غير متوفرة & متوفرة & \\
\hline$\% \% 9$ & $\% 91$ & 7 & 19 & حي \& ا تموز \\
\hline$\% 1$. & $\% 9$. & $\varepsilon$ & YI & حي الامام علي \\
\hline$\%$ & $\% \vee q$ & $\mathrm{~V}$ & 11 & حي الزهراء \\
\hline$\%$ Yo & $\% \vee 0$ & $\Lambda$ & IV & 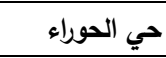 \\
\hline
\end{tabular}

ومن خلال الجدول( ؛ ) يلاحظ ان مستوى الخدمات التعليمية في جميع أحياء منطقة الدراسة جيدة فهي تتراوح بين

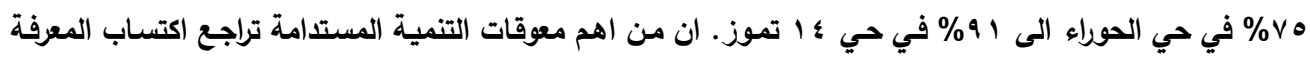

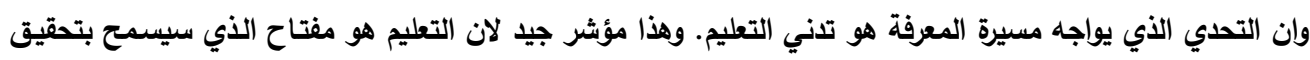

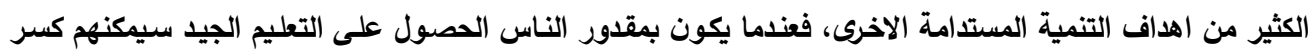

دائرة الفقر والحد من انعدام المساواة وتحقيق المساواة بين الجنسين. شكل (؛) : مؤشر مستوى خدمات التعليم في منطقة الدراسة

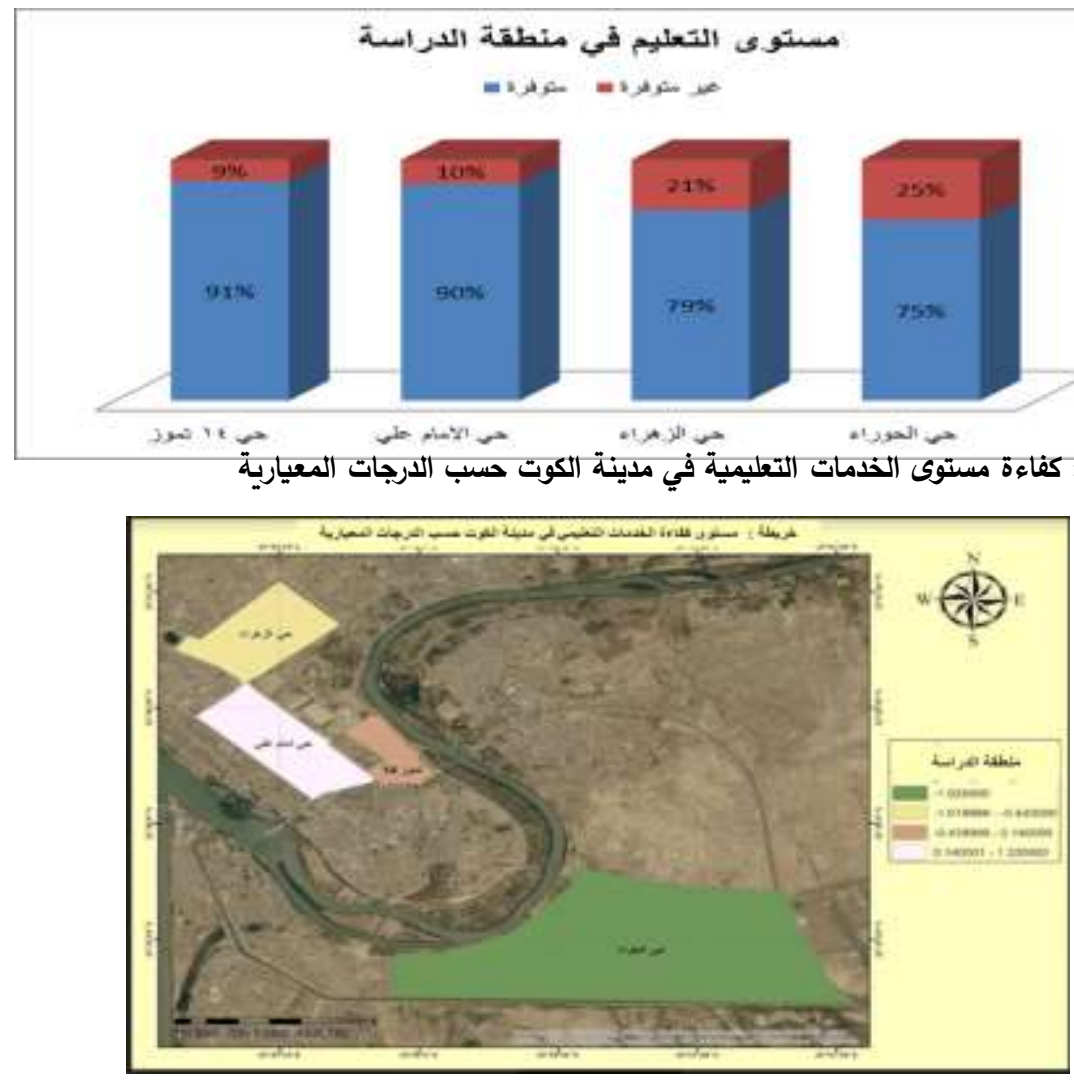

المصدر : صورة جوية من القمر الصناعي كوك بيرد التقت لمدينة الكوت مع معالجة الباحث 1 1 ـr ب ז 
العـــــــد الرابع والثثلاثون

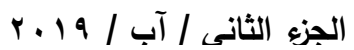

3)

I

issut 4253954

Nou cancoge

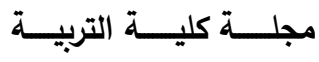

ثانيا : مؤشر الخدمات جدول (0) : التباين المكاني لمستوى الخدمات الصحية في منطقة الدراسة

\begin{tabular}{|c|c|c|c|c|c|c|c|c|}
\hline \multicolumn{4}{|c|}{ نسبة مستوى الذامات الصحية في المنطقة } & \multicolumn{4}{|c|}{ مستوى الخدمات الصحية } & \multirow[t]{2}{*}{ الاحياء السكنية } \\
\hline ضعيف & متوسط & جيد & جيد جدا & ضعيفة & متوسط & جيد & جيد جدا & \\
\hline$\%$. & $\%$ & $\%$ & $\% 9$ & $\cdot$ & $r$ & $r$. & $r$ & حي ؛ ا تموز \\
\hline$\% 10$ & $\% \leqslant \leqslant$ & $\%$ ro & $\%$ & 0 & 9 & $\Lambda$ & $r$ & حي الامام علي \\
\hline$\% 10$ & $\% 0^{\circ}$ & $\%$ \%r & $\%$ & $\circ$ & IY & $\Lambda$ & $\dot{.}$ & 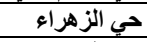 \\
\hline$\%$ \% & $\% \leqslant$ & $\% \leqslant \Lambda$ & $\%$. & $\varepsilon$ & 1. & 11 & . & حي الحوراء \\
\hline
\end{tabular}

يلاحظ من الجدول (0) ان ربع الاسر في منطقة الدراسـة محرومة من اشباع الحاجات الصحية الأساسية

وان الاحياء الأكثر حرمانا هي حي الحوراء وحي الزهراء شكل (ه).

شكل (ه): مؤشر مستوى الذدمة الصحية في منطقة الدراسة أنساء

\section{مستوى الخدمات الصحية في منطقة الدراسة}

ضسوفن

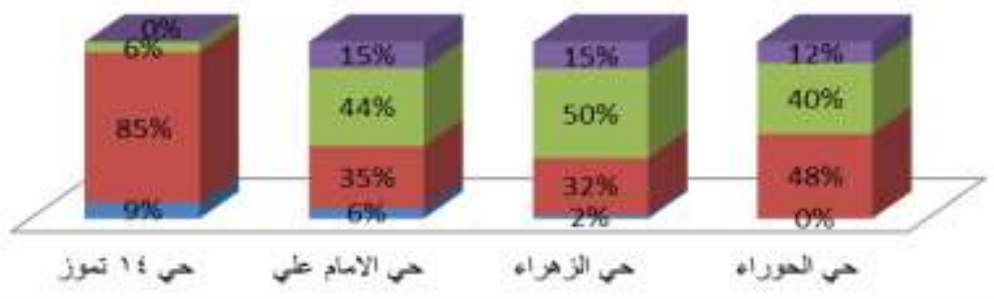


العــــــدد الرابع والثلاثون

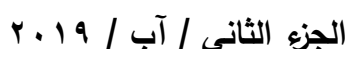
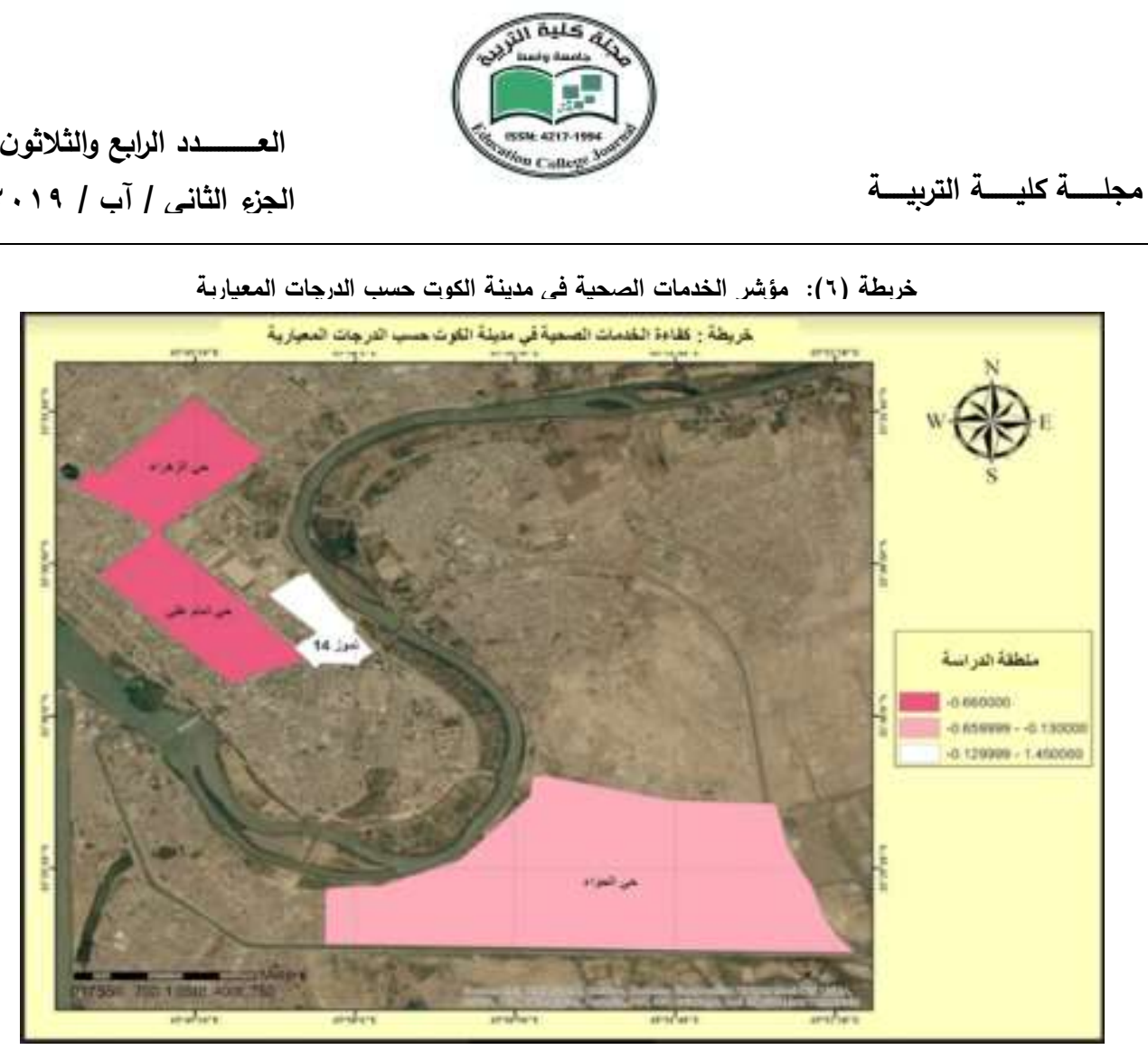

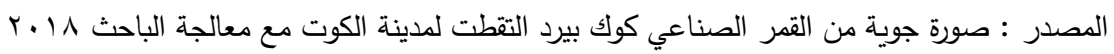

ثالثا : مؤشر توفز الخدمات الترفيهية المناطق الخضراء

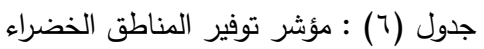

\begin{tabular}{|c|c|c|c|c|}
\hline \multicolumn{2}{|c|}{ نسبة" الرضا الن المناطق الخضر اء في منطقة الدراسة } & \multicolumn{2}{|c|}{ درجة الرضا عن المناطق الخضر اء في منطقة الدراسة } & \multirow[t]{2}{*}{ الاحياء السكنية } \\
\hline علدم الرضا & رضا & عدم رضا & رضا & \\
\hline$\% \vee \wedge$ & \%rr & IV & $\Lambda$ & حي ؛ ا تموز \\
\hline$\%$ \%॰ & $\% 10$ & r. & $\circ$ & حي الامام علي \\
\hline$\%$ vo & $\%$ Yo & 10 & 1. & 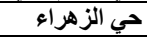 \\
\hline 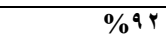 & $\%^{\wedge}$ & r & 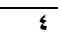 & 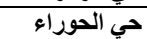 \\
\hline
\end{tabular}

نلاحظ من الجدول (†) ان نسبة الرضا عن المناطق الخضراء قليلة جدا فيما كانت اغلب الاسر في منطقة الدراسة

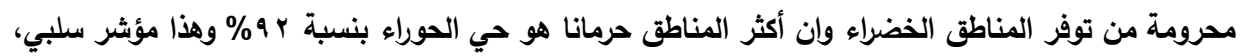

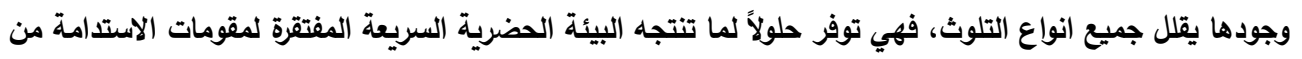

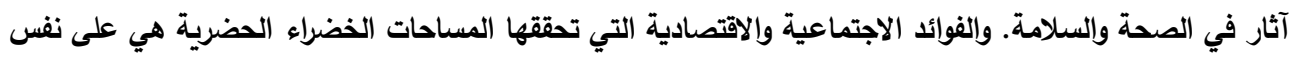

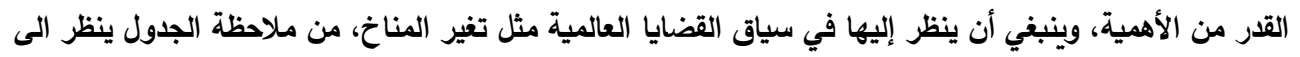

شكل (7). 
العــــــد الرابع والثلاثون

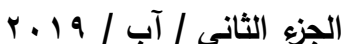

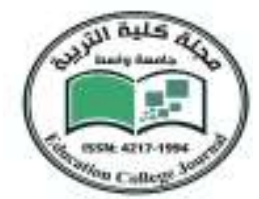

مجلــــة كليــــة التربيـــة

شكل (؟): مؤشر توفر المناطق الخضراء في منطقة الدراسة

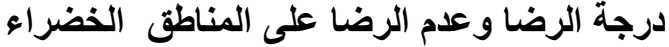

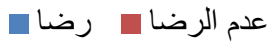

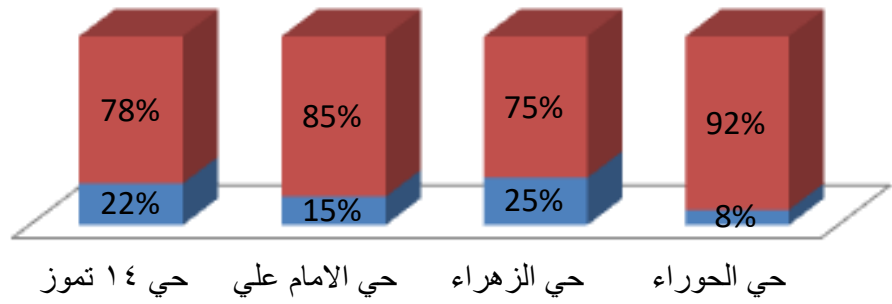

خريطة (V): مدى توفر المناطق الخضر اء في مدينة الكوت حسب الدرجات المعيارية

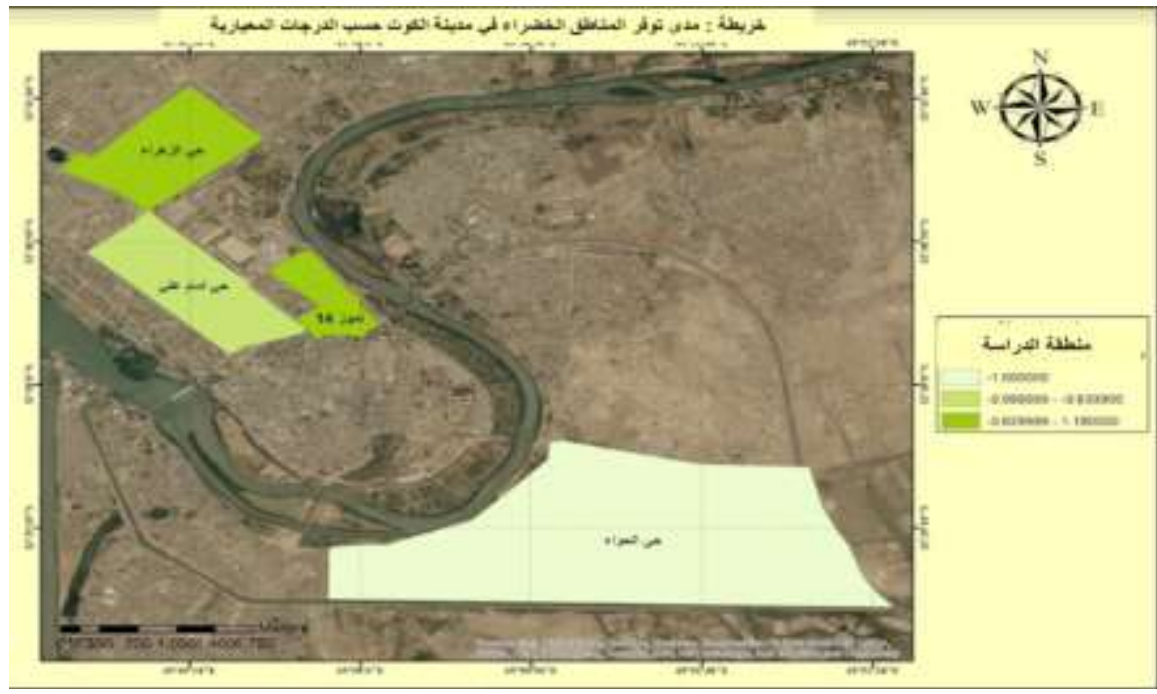

المصدر : صورة جوية من القمر الصناعي كوك بيرد التقت لمدينة الكوت مع معالجة الباحث 1 1 ـ r 
العـــــــد الرابع والثثلاثون

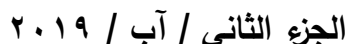

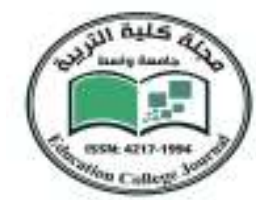

\section{رابعا : مؤشر الامن والامان}

جدول (V) : كفاءة الخدمات الامنية ومؤثراتها في منطقة الدراسة

\begin{tabular}{|c|c|c|c|c|c|c|c|c|}
\hline & \multicolumn{3}{|c|}{ نسبة الامن والامان في منطقة الدراسة } & \multicolumn{4}{|c|}{ الامن والامـان في منطقة الدراسة } & \multirow[t]{2}{*}{ الاحياء السكنية } \\
\hline ضعيف & متوسط & عالي & عالي جذا & ضعيفة & متوسط & عالّي & عالي جدا & \\
\hline$\%$ & $\% 11$ & $\% \wedge r$ & $\%$ & . & $\varepsilon$ & 19 & $r$ & حي ؛ ا تموز \\
\hline$\% 17$ & $\% \bullet V$ & $\%$ YV & $\%$ & 7 & 10 & $\mathrm{~V}$ & . & حي الامـام علي \\
\hline$\%$ & $\% \leqslant 1$ & $\% \circ r$ & $\%$ & $\varepsilon$ & 1. & 11 & . & حي الزهراء \\
\hline$\%$ & $\% 17$ & $\% \vee \wedge$ & $\%$ & $\varepsilon$ & 7 & 10 & . & حي الحوراء \\
\hline
\end{tabular}

ان لفقدان الامن أثار سلبية على أوضاع التنمية، فقد أظهر الاستبيان ان نسبة كبيرة من الاسرة اشارت الى توفر

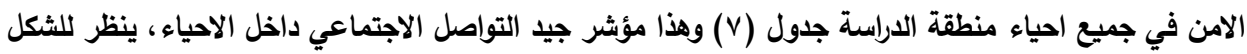

(v)

شكل (V) مؤشر الامن والأمان في منطقة الدراسة

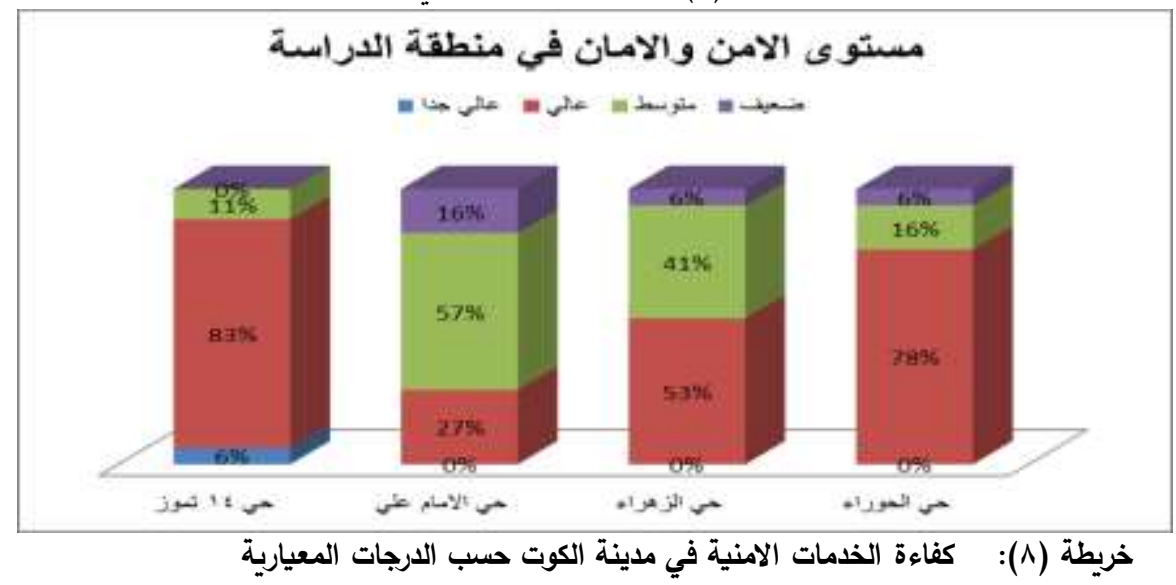




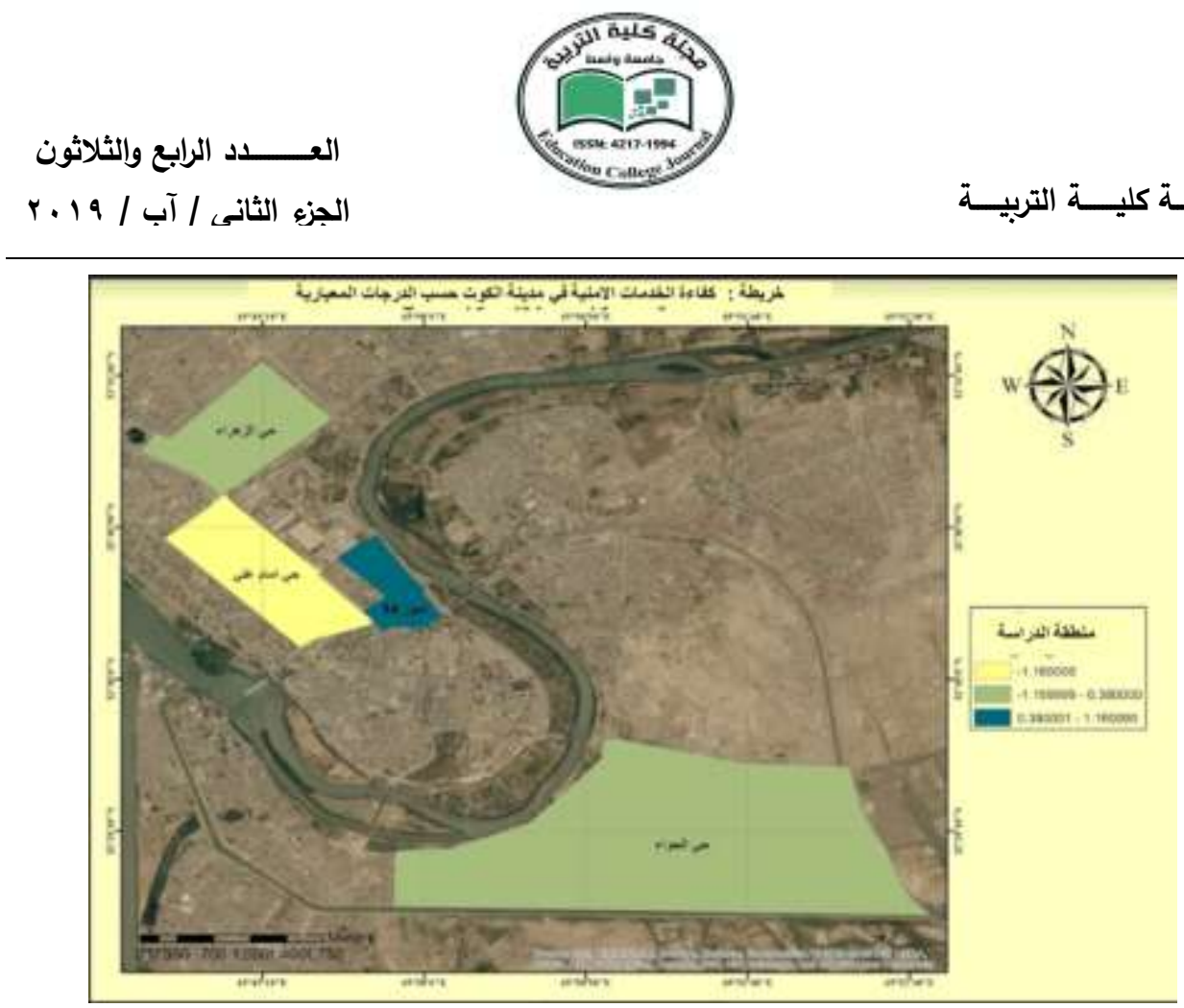

المصدر : صورة جوية من القمر الصناعي كوك بيرد التقطت لمدينة الكوت مع معالجة الباحث 1 1 ـ r

خامسا: مؤشر الدور الذي تلعبه الحكومة ومنظمة المجتمع المدني في توعية الافراد بالتتمية المستدامة جدول (^) : دور الدكومة ومنظمات المجتمع المدني في توعية الافراد بالتنمية المستدامة

\begin{tabular}{|c|c|c|c|c|c|c|c|c|}
\hline \multicolumn{4}{|r|}{ النسب } & \multicolumn{4}{|c|}{ المستدامة الحكومة ومنظمات المجتمع المدني في توعية الافراد بالتنمية } & \multirow[t]{2}{*}{ الاحياء السكنية } \\
\hline اخكرى & غير ضرورة & مساندة & ضرورة & اخرى تذكر & غير ضرورة & مساندة & ضرورة & \\
\hline$\%$ & $\% \wedge$ & $\% 1 \leq$ & $\% \vee \wedge$ & $\cdot$ & $r$ & $\varepsilon$ & 19 & حي ؛ ا تموز \\
\hline$\%$ & $\%$. & $\%$ & $\% 1 \ldots$ & . & . & . & ro & حي الامام على \\
\hline$\%$ & $\%$ & $\%$ & $\% 1 \ldots$ & $\cdot$ & $\cdot$ & $\cdot$ & ro & حي الزهراء \\
\hline$\%$ & $\%$ & $\%$ & $\% 1 \ldots$ & $\cdot$ & $\cdot$ & $\cdot$ & Yo & حي الحوراء \\
\hline
\end{tabular}

يلاحظ من الجدول(^) يجب ان يكون للحكومة ومنظمات المجتمع المدني دور في توعية الافراد بالتمية المستدامة حيث تسعى لتحقيق اشباع احتياجات المجتمع من خلال دورها الخدمي والخيري وتفعيل المشاركة الواعية والفاعلة في احداث التنمية المستدامة وتطوير الوعي بكافة أنواعه لدى جميع شرائح المجتمع ، ينظر لشكل (^). 
العـــــــد الرابع والثلاثون

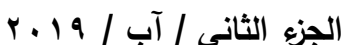

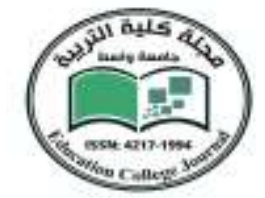

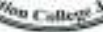

شكل (^): دور الحكومة ومنظمات المجتمع المدني في توعية الافراد بالتتمية المستدامة.

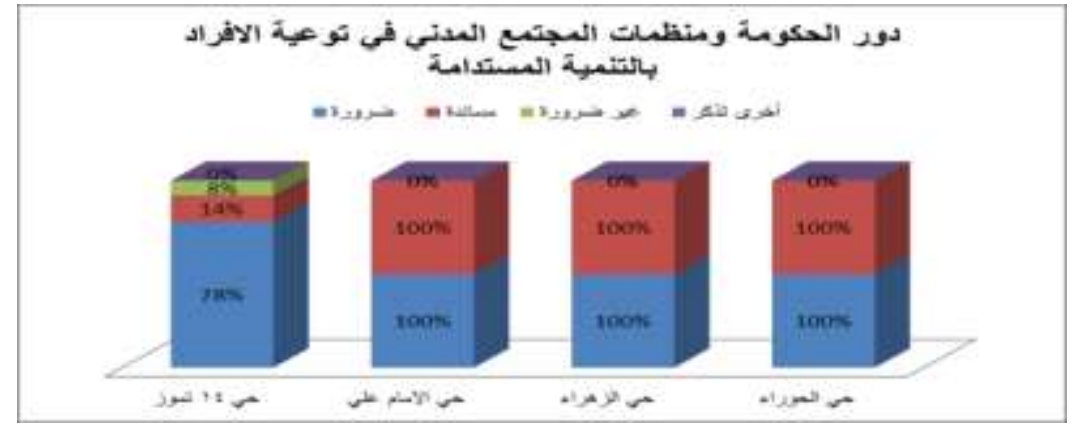

خريطة (9): دور الحكومة ومنظمات المجتمع المدني في مدينة الكوت حسب الارجات المعيارية

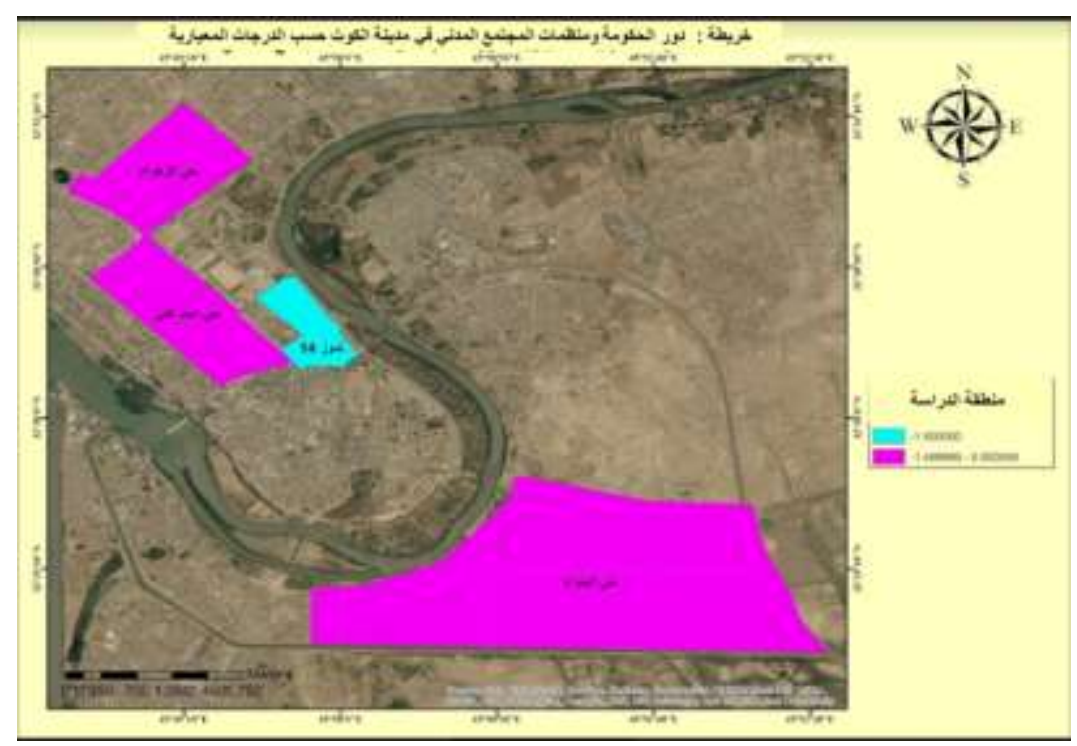

المصدر : صورة جوية من القمر الصناعي كوك بيرد التقطت لمدينة الكوت مع معالجة الباحث 1 1 ـ ؟ 
العـــــــد الرابع والثلاثون

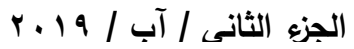

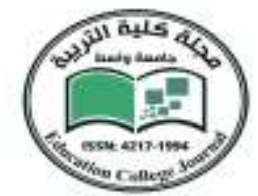

سادسا : مؤشر المرحلة الاراسية التي يتم فيها ادخال موضوع التوعية بالتنمية المستدامة

جدول (9) : في اي مرحلة دراسي يتم ادخال موضوع التوعية بالتنمية المستدامة

\begin{tabular}{|c|c|c|c|c|c|c|c|c|}
\hline & \multicolumn{3}{|c|}{ نسب المرحلة الدراسية } & & & \multicolumn{2}{|c|}{ المرحلة الاراسية } & \multirow[t]{2}{*}{ الاحياء السكنية } \\
\hline جامعي & اعدادي & متوسط & ابتلائي & جامعي & اعدادي & متوسط & ابتدائي & \\
\hline$\%$ & $\% r V$ & $\% 10$ & $\% \leqslant 0$ & $r$ & 7 & 0 & 11 & حي ؛ ا تموز \\
\hline$\%{ }^{r \Lambda}$ & $\%$. & $\%$ \%. & $\% \leqslant r$ & 9 & . & 7 & 1. & حي الامام علي \\
\hline$\%$. & $\%$. & $\% \leqslant 0$ & $\% 00$ & $\cdot$ & $\cdot$ & Ir & ir & حي الزهراء \\
\hline$\%$. & $\%$. & $\% \leqslant 0$ & $\% 00$ & . & . & Ir & ir & حي الحوراء \\
\hline
\end{tabular}

يلاحظ من خلال جدول (9) ان مرحلة الابتدائية هي التي يتم البدء منها بتدريس مادة التنمية المستدامة وهي

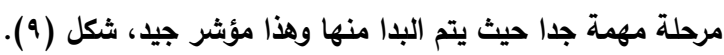

شكل (9): يوضح في اي مرحلة دراسية يتم ادخال موضوع التوعية (9) بالتنمية المستدامة

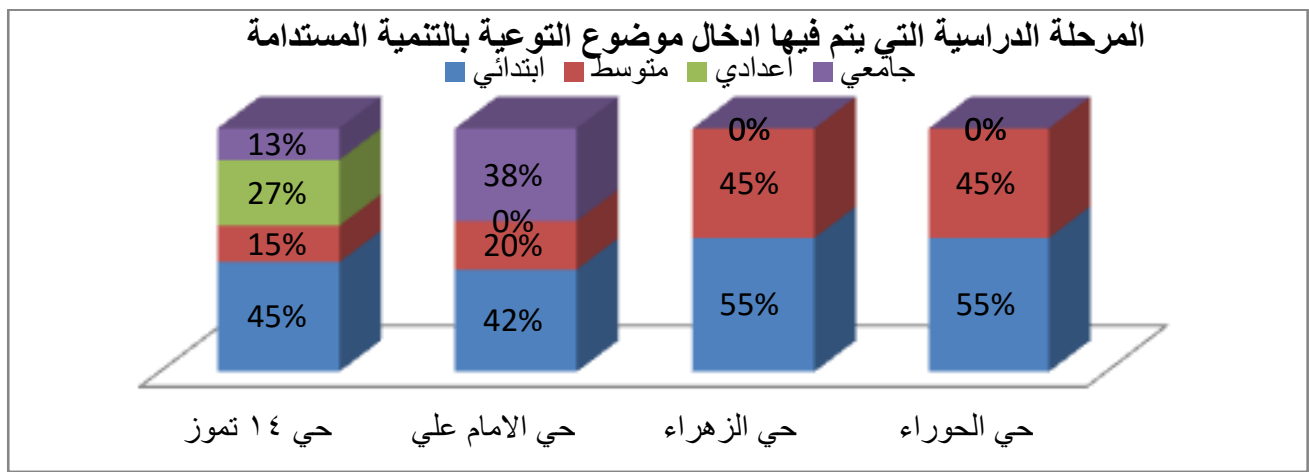

خريطة ( • 1): المرحلة الدراسية التي يتم فيها ادخال موضوع التنمية المستدامة في مدينة الكوت حسب الدرجات المعيارية

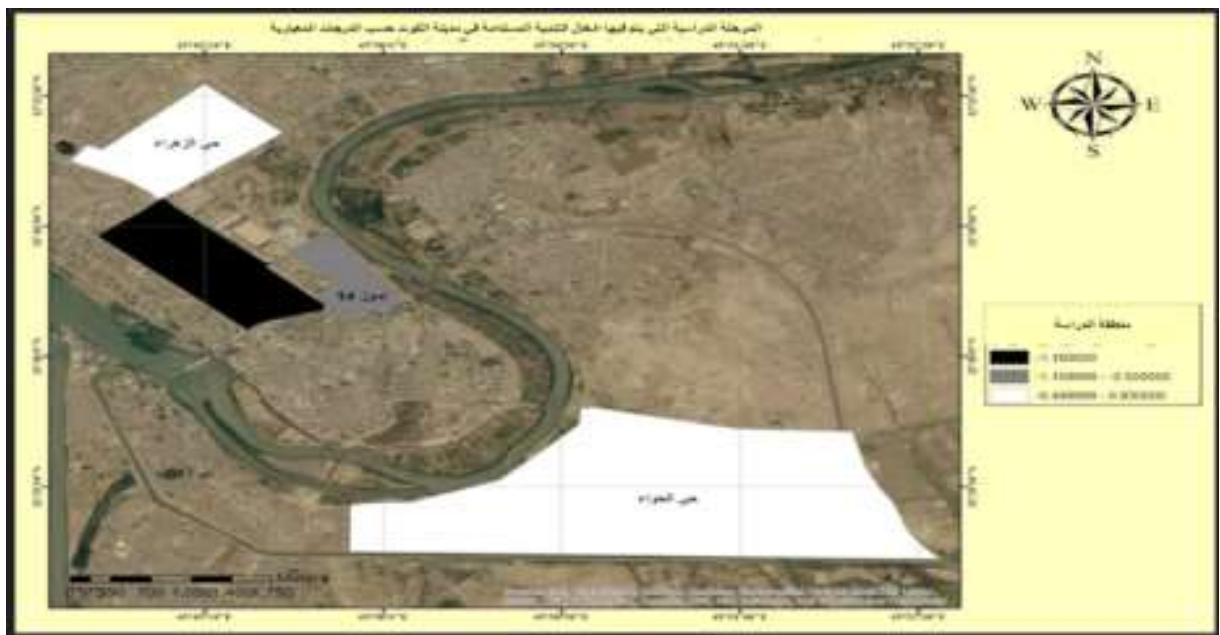

المصدر : صورة جوية من القمر الصناعي كوك بيرد التقطت لمدينة الكوت مع معالجة الباحث 1 ا ـ ؟ 
العـــــــد الرابع والثثلاثون

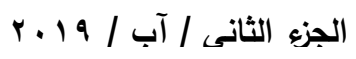

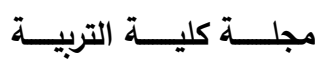

سابعا: مؤشر كيفية مواجهة الفقر والحد منه

جدول (• 1) : مؤشر كيفية مواجه الفقر والحدج منه

\begin{tabular}{|c|c|c|c|c|}
\hline \multicolumn{2}{|c|}{ نسب كيف نواجه الفقر والحد منه } & \multicolumn{2}{|c|}{ كيف نواجه الفقر والحـ منه } & \multirow[t]{2}{*}{ الاحياء السكنية } \\
\hline لونأهيليهن & انشأ دور للفقراء & تأهيليهم لوظائف منتجة & أنشاء دور للفقراء & \\
\hline$\% \vee r$ & $\%$ YV & IV & $\Lambda$ & حي ؛ ا تموز \\
\hline$\% 9 r$ & $\% \wedge$ & $r \cdot$ & $\varepsilon$ & حي الزهراء \\
\hline$\% 00$ & $\% \leq 0$ & ir & Ir & حي الامام علي \\
\hline$\%$ & $\%$ \% & 17 & 9 & حي الحوراء \\
\hline
\end{tabular}

يلاحظ من خلال الجدول ( • 1) في حل ومواجهة مشكلة الفقر من خلال تأهيلهم الى وظائف يحبونها للتقليل من الفقر

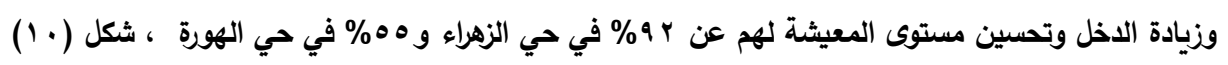

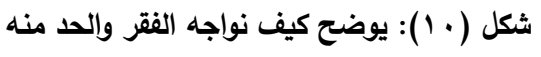

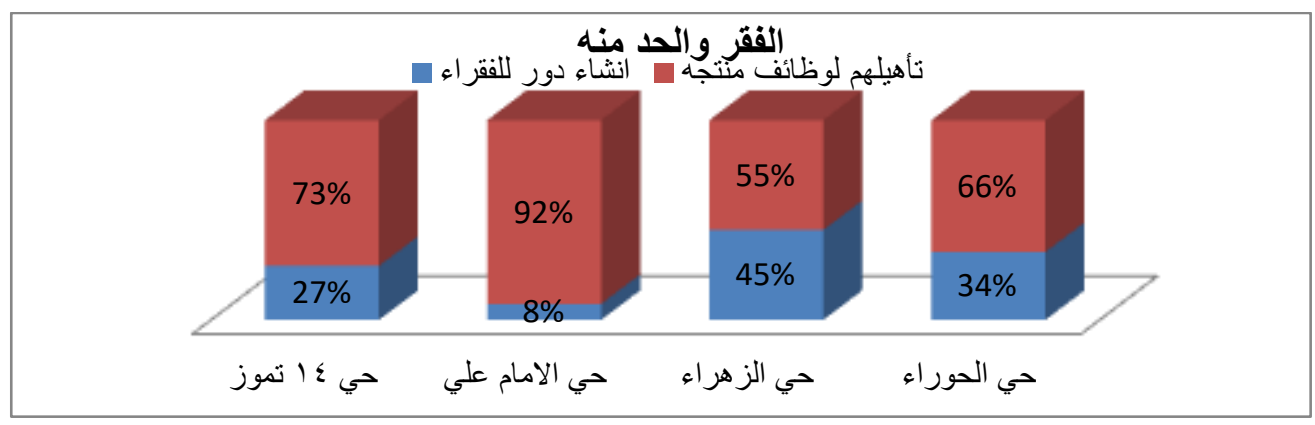


العـــــــد الرابع والثلاثون

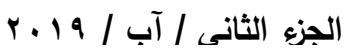

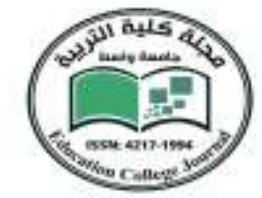

cuncing
مجلــــة كليــــة التربيـــة

\begin{tabular}{|c|c|c|c|c|}
\hline \multicolumn{2}{|c|}{ اختلاف العادات والتقاليا ودوره في المساواة بين } & \multicolumn{2}{|c|}{ دور اختلاف العادات والتقاليد في المساواة بين } & \multirow[t]{2}{*}{ السكنية القطاتية } \\
\hline$\gamma$ & نعم & لا & نعم & \\
\hline$\%$ \%r & $\% \vee V$ & 9 & 17 & حي ؛ ا تموز \\
\hline$\%{ }^{\prime \prime r}$ & $\% \wedge \wedge$ & • & $r \cdot$ & حي الامام علي \\
\hline$\% \vee$ & $\% 9 r$ & $r$ & Yr & حي الزهراء \\
\hline$\%$ Yq & $\% \wedge 1$ & $\Lambda$ & IV & حي الحوراء \\
\hline
\end{tabular}

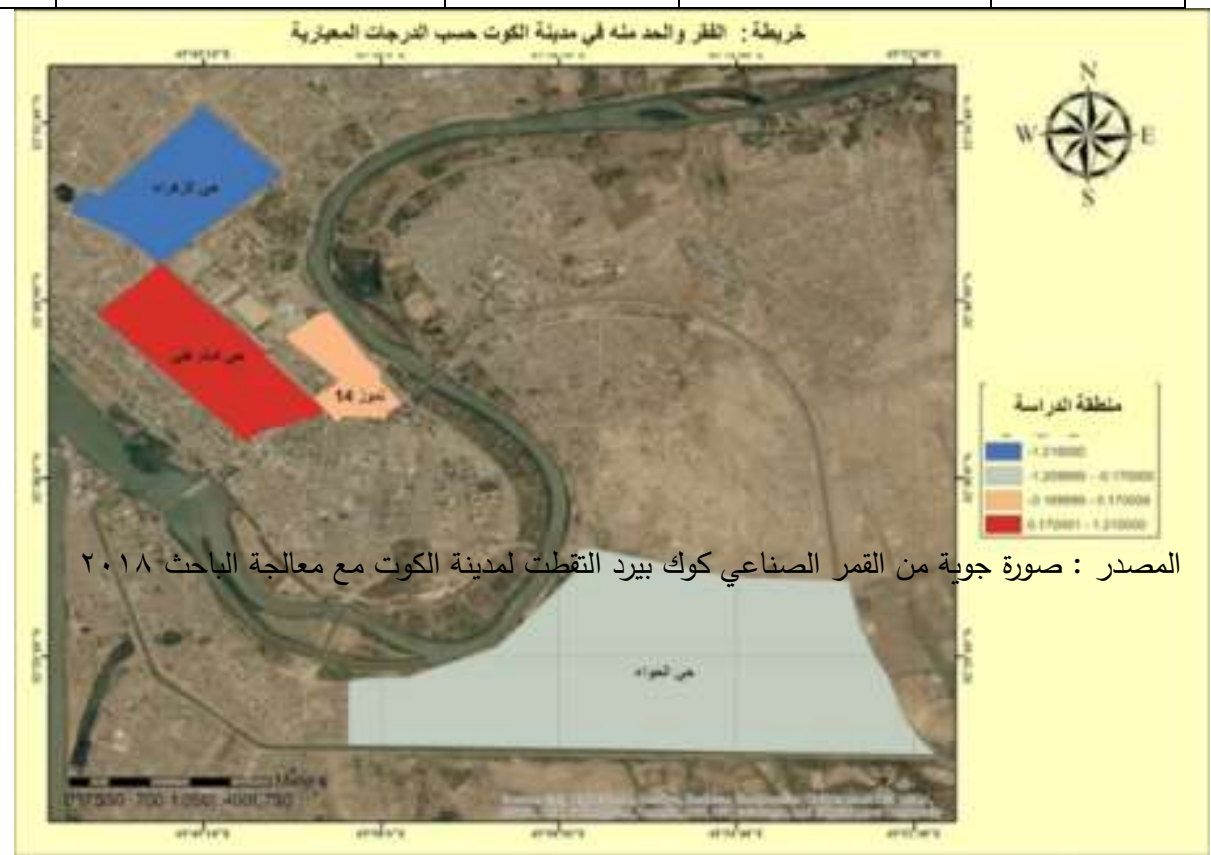

ثامنا : مؤشر اختلاف العادات والتقاليد في المساواة بين الجنسين

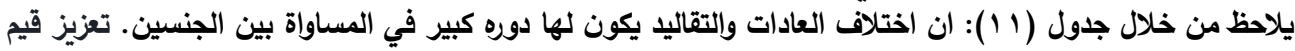

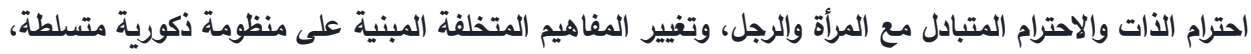

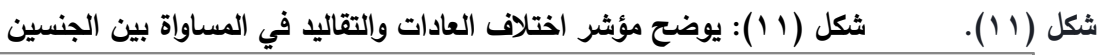

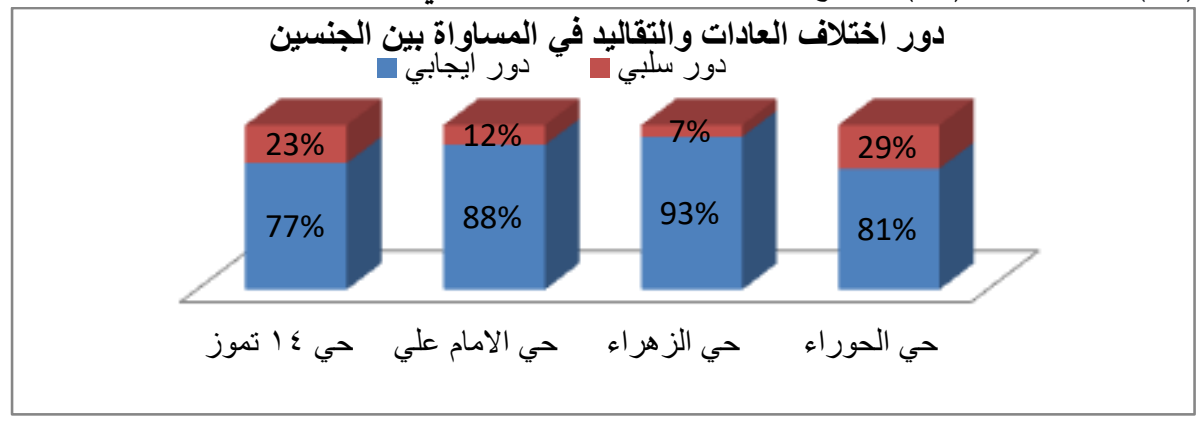




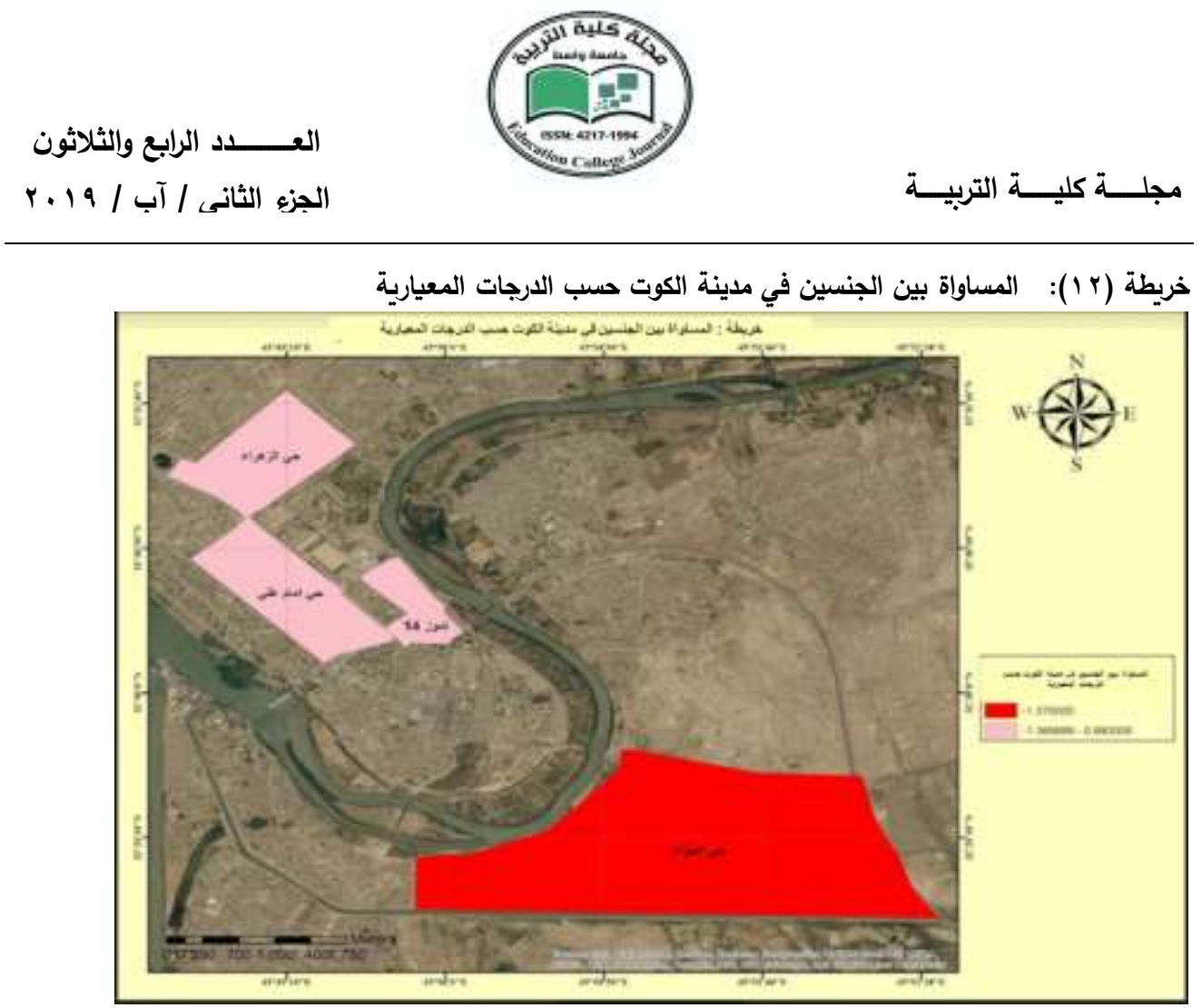

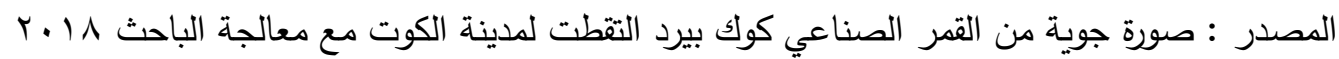

\section{الاستتتاجات والتوصيات}

تعـــ قضــية التتميـة قضـية محوريــة تعكس عــزم وإرادة شـعب لمسـتقبل أفضــل مـن

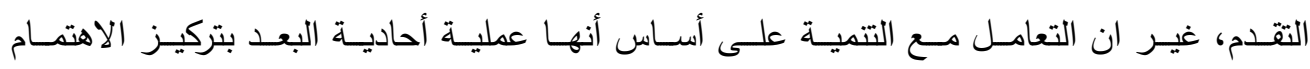

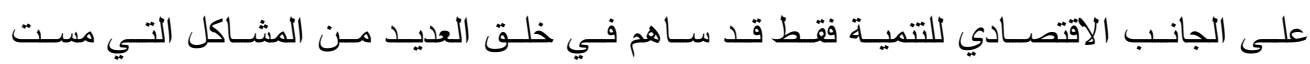

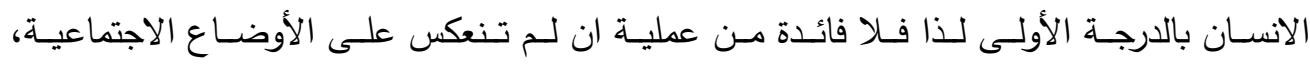

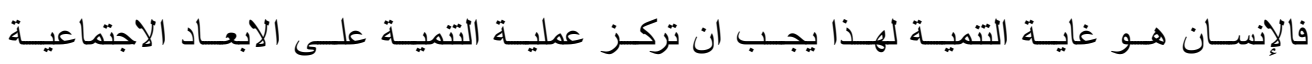

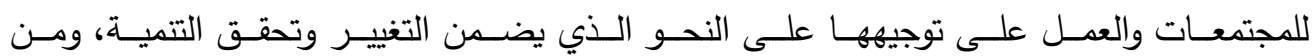
خلال البحث تم التوصل الى ولى 


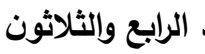

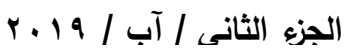

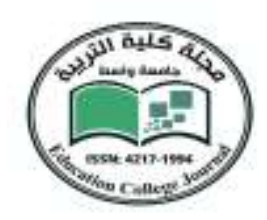

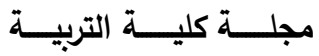

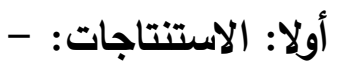

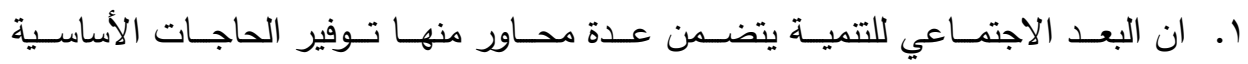

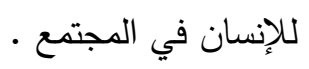

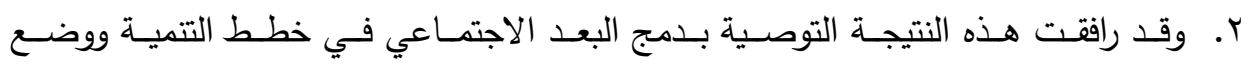

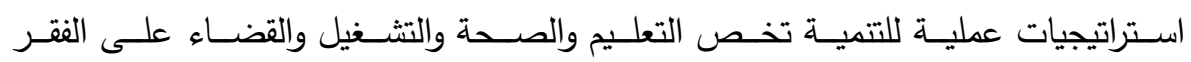
وتتمية القيم الاجتماعية الإيجابية.

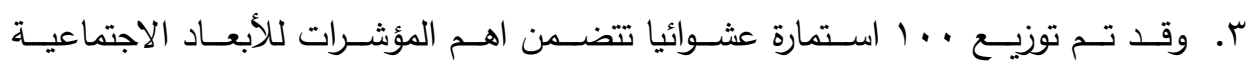
للتتميـة المستدامة في أربعـة احيـاء سكنية مختـارة مـن مستويات مختلفـة في مستويات

المعيشة.

ع. التعلـيم: وضـع اسـتراتيجية لتـوفير الخدمات التعليميـة ولكـل مراحلـه فـي كافـة الاحيـاء السكنية.

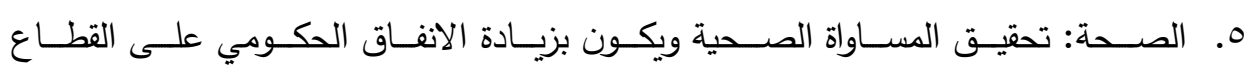
الصحة. ج. البطالـة: التأهيـل الحرفـي والمهنـي واكتســاب المهـارات والخبـرات المهنيـة مــع تـوفير البيئة القانونية والإدارية.

V. ان مدينة الكوت تعاني من البطالة بين الشباب وخاصة في حي الحوراء . ^. تزايـد نسـبة الفـر بـين سـكان مدينـة الكـوت وخاصــة الاحيـاء الثـعبية (حـي الحـوراء ،

$$
\text { حي الزهراء). }
$$

9. تعـاني مدينـة الكـوت تعـاني مـن نقـص فـي المنــاطق الخضــراء التـي يكـون لهـا دور اجتماعي فضلا عن معالجة المناخ. 
العـــــــد الرابع والثلاثون

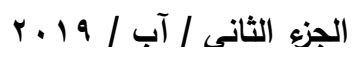

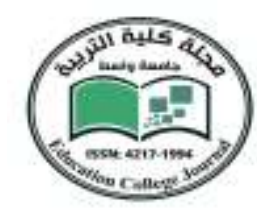

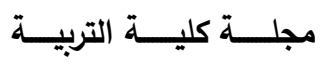

ثانيا: التوصيات

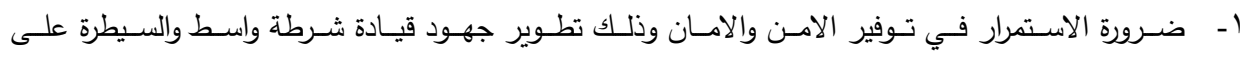

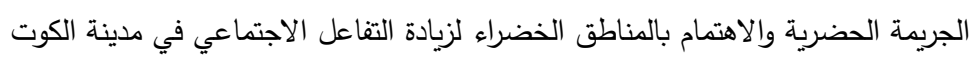

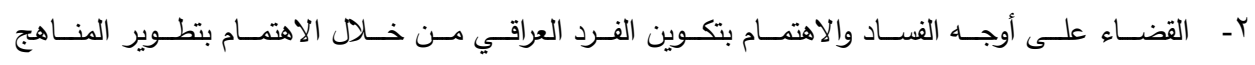

التعليمية والتربية العائلية.

r- ـ وضع استراتيجيات عملية للتمية تخص التعليم، الصحة، التشغيل، والقضاء على الفقر في المدينة.

ع- - احياء وتنمية القيم الاجتماعية والايجابية في مدينة الكوت.

\section{المصادر}

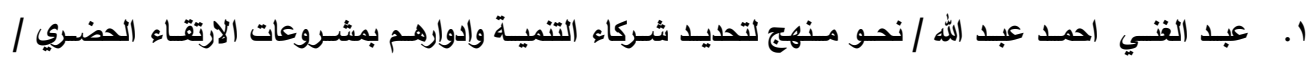

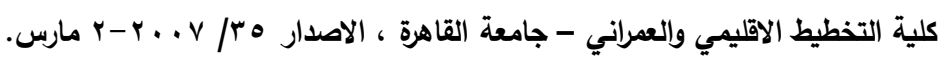

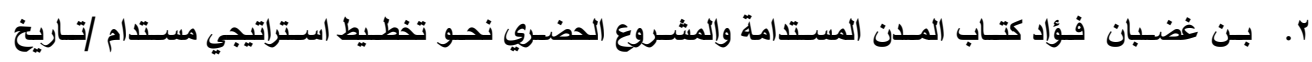

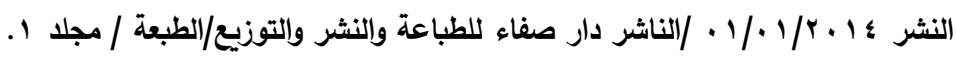

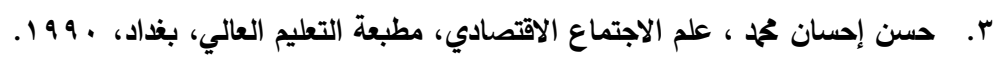

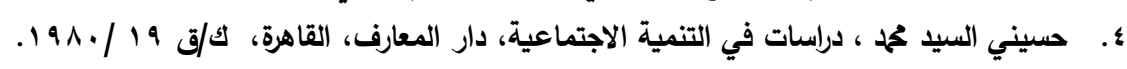

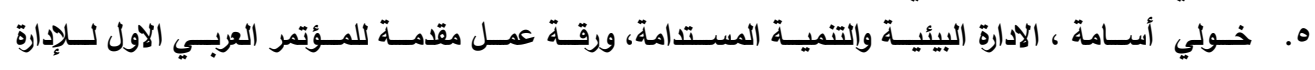

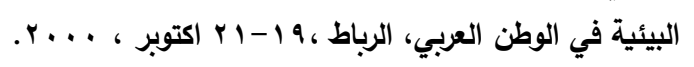

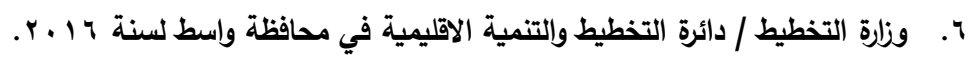

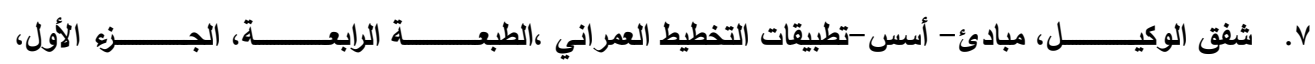

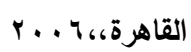

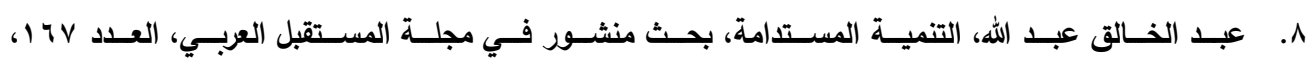

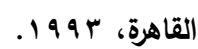

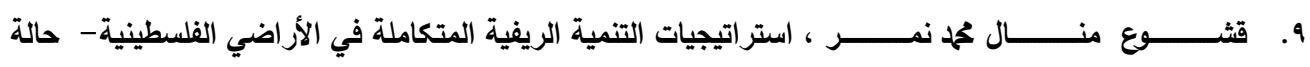
دراسية منطقة الشعر اوية "محافظة طولكرم ".

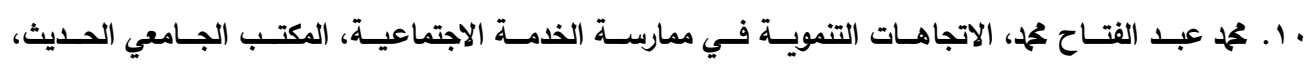

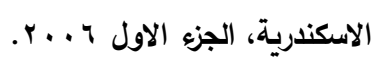

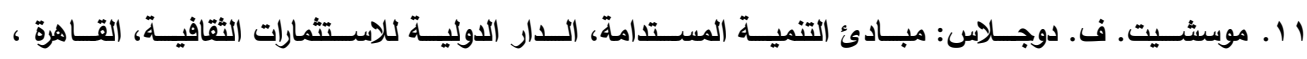

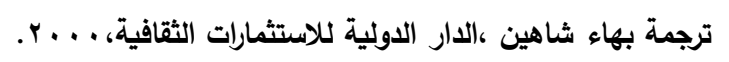

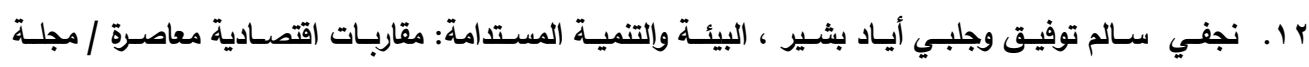

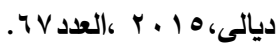


العـــــــد الرابع والثلاثون

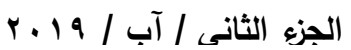

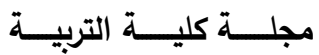

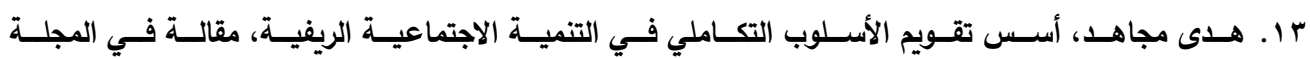

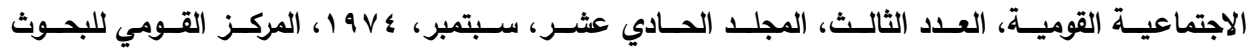
الاجتماعية والجنائية، جمهورية مصر العربية.

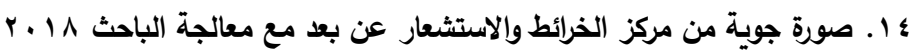

Chodak, Szymon, Societal Development, Oxford University Press, Ion. .10

New York, 1973 